This item was submitted to Loughborough's Research Repository by the author.

Items in Figshare are protected by copyright, with all rights reserved, unless otherwise indicated.

\title{
An investigation into zinc diffusion and tin whisker growth for electroplated tin deposits on brass
}

PLEASE CITE THE PUBLISHED VERSION

http://dx.doi.org/10.1007/s11664-014-2983-y

\section{PUBLISHER}

Springer / @ The Minerals, Metals \& Materials Society

VERSION

AM (Accepted Manuscript)

\section{PUBLISHER STATEMENT}

This work is made available according to the conditions of the Creative Commons Attribution-NonCommercialNoDerivatives 4.0 International (CC BY-NC-ND 4.0) licence. Full details of this licence are available at: https://creativecommons.org/licenses/by-nc-nd/4.0/

\section{LICENCE}

CC BY-NC-ND 4.0

\section{REPOSITORY RECORD}

Ashworth, Mark A., G.D. Wilcox, Rebecca L. Higginson, Richard J. Heath, and Changqing Liu. 2015. "An Investigation into Zinc Diffusion and Tin Whisker Growth for Electroplated Tin Deposits on Brass". figshare. https://hdl.handle.net/2134/16991. 
An investigation into zinc diffusion and tin whisker growth for electroplated tin deposits on brass

\author{
MARK A. ASHWORTH ${ }^{1}$, GEOFFREY D. WILCOX ${ }^{1}$, REBECCA L. HIGGINSON ${ }^{1}$, \\ RICHARD J. HEATH ${ }^{1}$ AND CHANGQING LIU ${ }^{2}$ \\ ${ }^{1}$ Department of Materials, Loughborough University, Loughborough, Leicestershire, LE11 \\ 3TU \\ ${ }^{2}$ School of Mechanical and Manufacturing Engineering, Loughborough University, \\ Loughborough, Leicestershire, LE11 3TU
}

Corresponding author:

Email: m.a.ashworth@lboro.ac.uk

Tel: $\quad$ +44 (0)1509 225406 


\section{ABSTRACT}

It is widely documented that whisker growth is more rapid for tin deposits on brass compared with deposits produced on other substrate materials, such as copper. As a result, studies investigating the effect of process variables on tin whisker formation are often conducted on brass substrates to take advantage of the increased whisker growth rates. Although it has been understood since the 1960's that the increased whisker growth results from zinc diffusion, to date there has not been any detailed analysis of the zinc/zinc oxide distribution at the surface of the tin deposit. Using a commercial bright tin electroplating bath, the formation of zinc oxide at the surface of tin deposits on brass has been investigated. The distribution of the zinc oxide and its development as a function of storage time has been studied. The effect of an electrochemical oxidation treatment, immediately after tin deposition, on zinc oxide formation and subsequent whisker growth has also been investigated. Analyses show that zinc oxide is present on the surface of the deposit within one day of electroplating. During storage at room temperature a network of zinc oxide is formed at the surface grain boundaries, the extent of which increases with time. The critical role that zinc diffusion plays in whisker growth for tin deposits on brass has been demonstrated by electrochemical oxidation of the tin shortly after electroplating. This develops a tin oxide film that is thicker than the native air formed oxide and subsequently serves as a diffusion barrier to zinc surface diffusion, thereby mitigating whisker growth.

Keywords: tin, electrodeposition, whisker growth, brass, zinc, diffusion 


\section{INTRODUCTION}

Following implementation of the Restriction of Hazardous Substances Directive 2002/95/EC (RoHS) [1] in 2006 prohibiting the use of lead in electronics there has been increasing concern about potential failures of electronic devices as a result of tin whisker growth. The move towards lead-free electronics manufacture has removed the only effective method of successfully mitigating against the growth of tin whiskers and led to renewed interest in developing alternative whisker mitigation strategies either through the development of new tin alloys, modification of the electroplating bath formulation or the use of conformal coatings. Typically, whisker related research is carried out on copper, brass or alloy 42 (Fe/42 Ni) substrates and it has long been established that tin deposits on brass substrates are more susceptible to whisker growth than equivalent deposits on copper or alloy 42. Many researchers utilise this to their benefit since it enables the effect of electrodeposition parameters and other process variables on whisker formation to be investigated within reasonable time frames [2-9]. The rapid and profuse whisker growth that ensues from tin deposition onto brass is also beneficial in the evaluation of conformal coatings as a potential whisker mitigation strategy [10].

The rapid whisker growth observed for tin deposits on brass results from zinc diffusion from the brass substrate to the surface of the deposit. Early work by Britton [11], using potential measurements and corrosion tests, showed that zinc was present on the surface of tin deposits on brass and that this was responsible for the accelerated whisker growth that was observed. Direct evidence for zinc diffusion to the surface of tin deposits on brass was later provided by Dunn using EDS analysis [12]. In the ensuing years, despite the numerous studies utilising tin deposits on brass, there appears to have been no detailed characterisation of the zinc distribution within the tin deposit or consideration of how this might influence whisker growth mechanisms; i.e. does the zinc diffusion merely accelerate whisker growth or does it 
change how the propensity to whisker formation is influenced by changes to the structure of the electrodeposited tin.

In the current study, the formation of zinc oxide on the surface of the electroplated tin and the distribution of zinc within the deposit has been investigated using scanning electron microscopy (SEM), energy dispersive x-ray spectroscopy (EDS), X-ray photoelectron spectroscopy (XPS) and Auger electron spectroscopy (AES). Electrochemical oxidation of the tin has also been studied to demonstrate the critical role that zinc oxide plays in whisker growth and to investigate its potential as a whisker mitigation strategy.

\section{EXPERIMENTAL}

Bright tin was electrodeposited onto copper (99.9\%, $0.1 \mathrm{~mm}$ thickness) and brass (63Cu/37Zn, $0.38 \mathrm{~mm}$ thickness) substrates using Tinmac Stannolyte (MacDermid, Birmingham, UK), a bright acid tin electroplating solution. Test coupons with dimensions $2 \mathrm{x}$ $4 \mathrm{~cm}$ were used with an electroplated area of $2 \times 2 \mathrm{~cm}$. The coupons were used in the assupplied condition with no additional polishing or grinding operations.

Electrodeposition was carried out using a 99.95\% Sn foil anode (0.25 mm). Immediately prior to deposition, all the substrates were degreased using acetone, pickled for 60 seconds in a $20 \% \mathrm{v} / \mathrm{v}$ solution of sulphuric acid (SG 1.83), rinsed in deionised water and dried using hot air. Direct current galvanostatic deposition was carried out using a SI 1286 Electrochemical Interface (Solartron Analytical, Farnborough, UK) whilst pulse plating was performed using an EG\&G (Princeton Applied Research, Oak Ridge, TN, USA) potentiostat/galvanostat Model 263A.

After deposition the samples were either stored at room temperature $\left(\sim 20^{\circ} \mathrm{C}\right)$ or exposed to elevated temperature and humidity $\left(55^{\circ} \mathrm{C}\right.$ and $85 \%$ relative humidity) to accelerate whisker growth. SEM/EDS analysis of the tin deposits was undertaken using a Leo 1530 VP FEG 
SEM (Carl Zeiss, Cambridge, UK) equipped with an X-Max $80 \mathrm{~mm}^{2}$ Detector (Oxford Instruments, Abingdon, UK). Surface analysis was performed using a K-Alpha X-ray Photoelectron Spectrometer (Thermo-Scientific, Waltham, MA, USA). Sputter profiling was performed using $200 \mathrm{eV}$ argon ions with an estimated etch rate of $\sim 0.6 \mathrm{~nm} \mathrm{~min}{ }^{-1}$. Auger electron spectroscopy (AES) was also undertaken, using a JAMP-7100 (JEOL (UK) Ltd., Welwyn Garden City, UK) instrument, to investigate the surface and bulk composition of the whiskers grown from tin deposits on brass. Analysis was performed using an electron beam accelerating voltage of $10 \mathrm{kV}$. Sputtering, to remove the surface oxide, was performed using $2 \mathrm{kV}$ Arions.

The zinc distribution within the tin deposit was investigated using cross-sectioned coatings. These were prepared by mounting in resin, grinding using silicon carbide papers (240-1200 grit) and polishing using $6 \mu \mathrm{m}$ and $3 \mu \mathrm{m}$ diamond suspensions. Final polishing was carried out using colloidal silica.

The effect of electrochemical oxidation of the tin deposit on whisker formation was assessed using $2 \mu \mathrm{m}$ tin deposits on brass. Electrochemical oxidation was performed in a $\mathrm{pH} 8.4$ borate buffer solution (9.55 $\mathrm{g} \mathrm{l}^{-1}$ sodium borate and $6.18 \mathrm{~g} \mathrm{l}^{-1}$ boric acid) at $1.2 \mathrm{~V}, 1.6 \mathrm{~V}$ and $2 \mathrm{~V}$ (vs. SCE). The composition and thickness of the oxide film was characterised by XPS analysis and sputter depth profiling after deposition and storage at ambient for 20 weeks. Whisker growth on the electrochemically oxidised samples and control samples, left to develop a native air formed oxide, was evaluated four months after deposition by optical and SEM analysis.

\section{RESULTS}

\section{Analysis of zinc oxide formation}


It was apparent from optical and SEM observations that whisker formation was greatly accelerated for tin deposits on brass substrates compared with copper. Examples of tin whisker formation on copper and brass substrates are shown in Figures 1 and 2, for deposits prepared by direct current deposition and pulse electroplating, respectively. Regardless of the deposition method, whisker growth was always greater for tin deposits on brass. The reason for the accelerated tin whisker formation is suggested by visual examination of the tin deposits after prolonged storage; tin deposits on brass are discoloured compared with equivalent deposits onto copper, which remain bright and free from tarnish (Figure 3). As demonstrated by Britton [11], this discolouration may be attributed to the formation of zinc oxide on the surface of the tin deposit. Diffusion of zinc to the deposit surface is shown to be extremely rapid; XPS analysis shows that zinc is present at the surface of a $2 \mu \mathrm{m}$ tin coating within 1 day of deposition (Figure 4a). There is no measurable chemical shift in the photoelectron peaks for zinc which make it impossible to distinguish between the metallic and oxidised states [13]. However, it can be established from the $\mathrm{L}_{3} \mathrm{M}_{4,5} \mathrm{M}_{4,5} \mathrm{Zn}$ Auger peaks, which are separated by a shift of $\sim 4.3 \mathrm{eV}$ between the metallic and oxidised states, that zinc is present in the form of an oxide (at a binding energy of $\sim 499.3 \mathrm{eV}$ ). The presence of metallic zinc cannot be firmly established since the Zn Auger peak is situated at a binding energy of $\sim 494.1 \mathrm{eV}$, which corresponds to the position of the $\mathrm{Sn} 3 \mathrm{~d}_{3}$ photoelectron peaks.

After storage at room temperature for $\sim 5$ months the measured zinc concentration on the surface is increased (Figure 4b) and the analysed $\mathrm{Zn}: \mathrm{Sn}$ ratios on the surface of the deposit are $~ 1: 3$ and 1:1 after 1 day and 5 months, respectively. The in-depth distribution of Sn and $\mathrm{Zn}$ at the surface of a 1 day old $2 \mu \mathrm{m}$ tin deposit on brass is shown in Figure 5. The sputter depth profile indicates that the tin oxide on the surface of the deposit is very thin and that zinc content reaches a maximum after $\sim 40$ seconds sputter (estimated to be approximately $0.4 \mathrm{~nm}$ below the original surface of the deposit). At this depth, the oxygen signal is $~ 23$ at\% whilst 
the contribution due to Sn oxide is $\sim 10$ at\%. If it is assumed that the Sn oxide formed is $\mathrm{SnO}$, then the remainder of the oxygen signal must be associated with $\mathrm{Zn}$, which is consistent with the observation of the Zn oxide Auger peak in the survey and high resolution scan of the Sn 3d5 peak. However, if the oxide formed is $\mathrm{SnO}_{2}$, the proportion of oxygen signal associated with $\mathrm{Zn}$ would be greatly reduced. The location of the peak Zn concentration suggests that any $\mathrm{Zn}$ oxide is formed at the interface between the Sn oxide and the underlying Sn metal. A zinc signal persists to a sputter depth of $\sim 4 \mathrm{~nm}$ (400 seconds), which may indicate it is present on the Sn grain boundaries adjacent to the surface of the deposit; however, it is not known whether $\mathrm{Zn}$ is present at this depth in the metallic or oxidised state (although the oxygen signal is very low at sputter times greater than $400 \mathrm{~s}$ ).

A more comprehensive understanding of the zinc oxide distribution on the surface of the tin is obtained from SEM/EDS analysis of the surface of deposits. SEM/EDS analysis shows that the Sn grain boundaries at the surface of the tin are decorated with zinc oxide, this is illustrated in Figure 6, which shows the surface of a $5 \mu \mathrm{m}$ deposit on brass, prepared at $5 \mathrm{~mA}$ $\mathrm{cm}^{-2}$, after storage at room temperature for 6 months. SEM/EDS maps clearly show that all of the grain boundaries, which show a dark contrast when imaged using secondary electrons, were fully decorated with zinc oxide after 6 months storage. Higher magnification imaging of the grain boundary regions (Figure 7) indicates that cracks may be present within the grain boundary zinc oxide. After prolonged storage the extent of the grain boundary zinc oxide has increased and in certain regions almost the entire tin grain surface is consumed; illustrated in Figure 8 for a $5 \mu \mathrm{m}$ tin deposit after storage for 14 months. The impact of the zinc oxide formation on whisker growth is suggested by the SEM image and elemental x-ray maps in Figure 9. The short whisker / eruptions observed on the surface of the deposit are associated with individual grains and the $\mathrm{Zn} \mathrm{L} \alpha$ and $\mathrm{O} \mathrm{K} \alpha \mathrm{x}$-ray maps show that zinc oxide is present around the grain perimeter at the tip of the whisker. It is interesting to note that the whisker 
grains typically show less zinc oxide coverage than the surrounding grains (illustrated in Figures 8 and 9).

A cross-section obtained from a $10 \mu \mathrm{m}$ deposit after 10 months storage at room temperature (Figure 10) shows that the grain boundary zinc oxide at the surface of the deposit penetrates a significant distance into the deposit $(>0.5 \mu \mathrm{m})$. It also shows that zinc is present along the grain boundaries throughout the thickness of the deposit. Analysis of the EDS map for oxygen also suggests that the outward diffusion of zinc from the substrate was accompanied by the inward diffusion of oxygen and that zinc oxide may be present at the grain boundaries within the tin deposit. It is possible, however, that the oxidation of the zinc present at the grain boundaries within the deposit occurred after the cross section was prepared and polished.

In whisker growth studies, exposure to elevated temperature and humidity conditions is often employed to accelerate whisker growth. Under these conditions zinc diffusion and subsequent oxide formation are greatly accelerated. Figure 11 shows SEM/EDS maps obtained from a cross sectioned $3 \mu \mathrm{m}$ tin deposit on brass $\left(20 \mathrm{~mA} \mathrm{~cm}{ }^{-2}\right)$ after 28 days at $55{ }^{\circ} \mathrm{C}$ and $85 \%$ relative humidity followed by 3 months storage at room temperature. Exposure to elevated temperatures and humidity has resulted in pronounced zinc (and oxygen) enrichment at the grain boundaries within the deposit and at the interface between the tin deposit and the substrate. It is also interesting to note that the $\mathrm{Cu}_{6} \mathrm{Sn}_{5}$ intermetallic was formed within both the tin deposit and the copper substrate (assuming that the zinc enriched layer represents the position of the original interface between the coating and the substrate).

The consequence of the increased zinc diffusion, and subsequent oxide formation, is a significant increase in whisker growth rates for samples exposed to elevated temperature / humidity compared with those stored at room temperature. This is illustrated in Figure 12, which compares the surface of a sample stored at room temperature for 44 days with one 
stored partly at elevated temperature and humidity $\left(28\right.$ days at $55^{\circ} \mathrm{C} / 85 \% \mathrm{RH}+16$ days at ambient). Long filament whiskers, in excess of $100 \mu \mathrm{m}$, are present on the sample stored for 28 days at elevated temperature/humidity (Figure 12a) whilst the sample stored at room temperature remains free of whiskers (Figure 12b). The explanation for this disparate behaviour is evident in Figures 12 (c) and (d), which show that the grain boundaries of the sample stored at room temperature remain free of zinc oxide whilst those of the heat treated samples are covered in zinc oxide. For tin deposits on copper, results obtained in the current study indicate that there is no obvious difference in whisker growth rates for samples stored for up to 5000 hours at $55{ }^{\circ} \mathrm{C} / 85 \%$ relative humidity compared with those stored at room temperature, i.e. exposure to elevated temperature does not have the same influence for tin deposits on copper as it does with brass.

Auger electron spectroscopy was performed, on a tin deposit on brass stored at room temperature for $~ 14$ months, to investigate both the surface and bulk composition of the whiskers, i.e. is Zn incorporated into the whisker. Analysis of the whisker surface prior to sputtering (Figure 13a) showed that, in addition to Sn and O peaks, strong Zn LMM peaks were also present. The measured kinetic energy of the Zn peak $(\sim 988 \mathrm{eV})$ indicates that $\mathrm{Zn}$ is present as $\mathrm{ZnO}$ [13]. Considering the relative sensitivity factors of $\mathrm{Zn}$ and $\mathrm{Sn}$, the ratio of $\mathrm{Zn:Sn}$ on the whisker surface is $\sim 3: 2$. Following a brief sputter, to remove carbon contamination, the intensity of the Zn peak was considerably reduced. Further sputtering resulted in the disappearance of the peaks corresponding to Zn (Figure 13b). These results show that $\mathrm{ZnO}$ formation occurs on the surface of tin whiskers when tin is electrodeposited onto brass; however, no $\mathrm{Zn}$ is incorporated into the bulk of the whisker.

\section{Whisker mitigation by prevention of zinc oxide formation}

To verify the significant role that zinc oxide formation plays in the growth of tin whiskers experiments were designed to prevent its formation. This was achieved by preferentially 
forming a relatively thick tin oxide immediately after deposition by electrochemical oxidation in a $\mathrm{pH} 8.4$ borate buffer solution. XPS analysis of electrochemically oxidised samples showed that the Zn content on the surface of the tin deposits was greatly reduced compared with control samples left to grow a native air formed oxide. Figure 14 shows an XPS survey scan for a sample electrochemically oxidised at $1.2 \mathrm{~V}$ vs. SCE, which indicated a Zn content of $\sim 1$ at $\%$ at the deposit surface. This can be compared with the survey scan for the native air formed oxide given in Figure 4. For samples oxidised at higher potentials (1.6 and $2 \mathrm{~V}$ vs. SCE) the analysed Zn content was further reduced to below 0.5 at\%. The high resolution Sn $3 \mathrm{~d} 5$ scans in Figure 15 show that, one day after deposition, the oxide formed at $1.2 \mathrm{~V}$ vs. SCE was significantly thicker than the initial native air formed oxide and also thicker than that present after $\sim 5$ months storage at room temperature, i.e. the intensity of the Sn metal peak was considerably reduced in the case of the electrochemically oxidised tin deposit. The binding energies of the Sn oxide peaks for the native air formed oxides $(\sim 487.0 \mathrm{eV})$ and each of the electrochemically formed oxides $(\sim 487.3 \mathrm{eV})$ were similar suggesting that the same oxide species was formed in all cases.

Optical and SEM analysis 5 months after deposition showed a clear difference in whisker formation between samples with electrochemically formed and native air formed oxides. Results show that whisker formation was prevented on all the samples with electrochemically oxidised surfaces whilst whiskers were present on each of the samples with air formed oxides. This is illustrated in Figure 16, which compares the surface of a sample with an air formed oxide with one having an oxide formed electrochemically at $1.2 \mathrm{~V}$ vs. SCE.

The basis for the improved whisker resistance demonstrated by the electrochemically oxidised samples is revealed by XPS analysis after storage at room temperature for 20 weeks. Figure 17 shows that although the measured zinc content at the deposit surface has increased slightly ( 1.8 at. \%) it is still greatly reduced compared with samples left to develop a 
natural air formed oxide. This indicates that the electrochemically formed tin oxide has suppressed the formation of zinc oxide on the surface of the deposit. This premise is supported by SEM analysis, which shows that formation of the grain boundary zinc oxide has been prevented on the surface of all the electrochemically oxidised samples.

An XPS sputter depth profile through the electrochemical oxide formed at $1.2 \mathrm{~V}$ vs. SCE after $\sim 9$ months storage is presented in Figure 18. The data shows that less than 2 at $\% \mathrm{Zn}$ is detected during the first 50 seconds sputter time but increases to reach a maximum of $\sim 23$ at\% after $\sim 200$ seconds sputter (estimated to be $\sim 2 \mathrm{~nm}$ beneath original surface). Beyond this depth, the Zn content gradually reduces until it reaches $\sim 3$ at $\%$ after $\sim 600$ seconds sputter. From the location of the peak zinc concentration in Figure 18 ( 200 s sputter) it can be deduced that zinc is present beneath the electrochemically formed tin oxide film. At this depth the tin content (in the oxidised state) is 16 at\% whilst the oxygen content is $\sim 29$ at\%, which if the stoichiometry of the oxide is $\mathrm{SnO}$, would indicate that zinc ( $\sim 22$ at \%) is present as both metal and oxide. If, however, $\mathrm{SnO}_{2}$ was formed then only metallic zinc would be present.

The oxidation state of the Sn cannot be established conclusively due to the small difference in binding energy between $\mathrm{SnO}$ and $\mathrm{SnO}_{2}$ and the overlapping range of values reported for these phases within the literature [14]. However, the binding energy of the tin oxide determined within this study (487.3 eV) lies within the range of values more typically associated with $\mathrm{SnO}_{2}$ [14]. Furthermore, a binding energy of $487.3 \mathrm{eV}$ was also reported by Zhang and Ruythooren [15] for a native oxide formed on electroplated tin deposits and attributed to $\mathrm{SnO}_{2}$, whilst a peak at $486.4 \mathrm{eV}$ was associated with $\mathrm{SnO}$.

\section{DISCUSSION}

\section{Zinc oxide formation}


Results obtained in the current study have demonstrated that tin electrodeposits on brass substrates are markedly more susceptible to rapid whisker formation than equivalent deposits on pure copper. The rapid whisker growth of the former is in agreement with most other studies $[3,7,12]$. It is interesting to note, however, that reduced whisker growth for tin deposits on brass compared with pure copper was reported by Miller et al. [16]. This was attributed to a reduction in the amount of $\mathrm{Cu}_{6} \mathrm{Sn}_{5}$ intermetallic formed at the interface in the presence of zinc.

SEM and XPS analyses have provided clear evidence that zinc oxide formation on the surface of the deposit is responsible for this accelerated whisker growth. Zn diffusion from the brass substrate to the surface of the deposit occurs rapidly and zinc is detected at the surface of the deposit within one day of deposition. With time, the surface zinc increases and the grain boundaries on the surface of the deposit become coated with zinc oxide. With increased storage time the zinc oxide spreads to entirely cover the surface of some grains. The presence of zinc on the surface of tin deposits on brass was also observed in an earlier study by Fujiwara and Kawanaka using Auger electron spectroscopy (AES) [17]. Zinc oxide formation at the surface grain boundaries of a tin deposit on brass, with a distribution similar to that illustrated in Figure 6, was also demonstrated by Sakuyama and Kutami [18] using AES elemental mapping. High zinc contents on the surface of tin deposits on brass were also observed by Dunn using SEM / EDS analysis [12]. In the present study, AES analysis showed that whilst Zn (oxide) was present on the whisker surface no Zn was present within the bulk of the whisker, i.e. the whiskers are comprised of pure tin. This is consistent with earlier observations by Fujiwara and Kawanaka [17].

Analysis of cross sectioned deposits suggests that the outward diffusion of zinc to the deposit surface is accompanied by the inward diffusion of oxygen down the tin grain boundaries, which results in the formation of zinc oxide. As shown in Figure 11, zinc oxide formation at 
grain boundaries within the tin is particularly evident on samples exposed to elevated temperature and humidity. A possible model for zinc oxide formation is shown schematically in Figure 19. Within 1 day of deposition, zinc oxide is formed at the surface of the deposit beneath the layer of tin oxide, i.e. at the tin oxide-tin metal interface (Figure 5). With an increase in storage time, zinc oxide builds up at the surface grain boundaries (as shown in Figure 6). With prolonged storage, the zinc oxide extends into the grain interiors on the surface of the deposit (Figure 8). There is also evidence to suggest that zinc oxide also penetrates down the grain boundaries into the tin deposit (Figure 10).

The critical role that zinc oxide formation has on whisker formation was demonstrated by electrochemical oxidation studies in which a comparatively thick tin oxide was formed on the tin deposit surface shortly after deposition. XPS analysis of the electrochemically oxidised samples after 9 months storage showed that the tin oxide functioned as a diffusion barrier, which prevented zinc from reaching the surface of the deposit. By preventing the formation of zinc oxide on the surface of the tin deposit whisker growth has been successfully mitigated. Whether the Zn, present at the interface between the electrochemically formed Sn oxide and the underlying metallic Sn, is in the oxidised or metallic state is dependent on the stoichiometry of the $\mathrm{Sn}$ oxide; if $\mathrm{SnO}_{2}$ is formed then $\mathrm{Zn}$ is primarily present in metallic form. Conversely, if $\mathrm{SnO}$ is formed then at least a proportion of the $\mathrm{Zn}$ must be present in the oxidised state. Further XPS studies are in progress to fully characterise the electrochemically formed tin oxide.

\section{Implications for whisker growth}

The formation of zinc oxide on the surface of the deposit will have two principal effects; firstly, it will lead to the development of residual stresses within the deposit and secondly it will cause the grain boundaries within the deposit to be pinned. Grain boundary pinning will 
immobilise the tin deposit and prevent relaxation of residual stresses by grain boundary migration or recrystallization [19], thereby favouring whisker growth. Thus, zinc oxide formation both increases stress within the deposit and prevents relaxation by mechanisms other than whisker growth. It is evident from comparative studies carried out for tin deposits on copper that whisker growth due to zinc diffusion is more significant than the effects of other factors such as intermetallic formation or residual stresses from electroplating, i.e. deposition parameters that give rise to rapid and profuse whisker growth for tin deposits on brass do not result in whisker growth for tin deposits on copper. This suggests that caution should be exercised when interpreting the results from whisker growth studies using tin deposits on brass if copper substrates are to be used in the application for which the tin deposit is being evaluated. Changes to the structure of the deposit that result in more rapid zinc diffusion are likely to result in accelerated whisker growth; it does not necessarily follow that the structure of the deposit is itself inherently more prone to whisker growth. The importance of zinc diffusion on whisker growth may also have implications for studies whose aim is to evaluate the whisker resistance of conformal coating materials using tin deposits on brass. If the coating material influences the availability of oxygen / moisture at the surface of the deposit then rate at which zinc oxidation occurs will be affected and there will be a chemical effect on whisker growth as well as a purely mechanical effect due to the physical properties of the coating. Potentially, this could change the whisker growth rate compared with uncoated deposits. Diffusion of zinc beneath conformal coatings was reported by Woodrow and Ledbury [10] who observed zinc and oxygen rich regions ('zinc rings') around odd-shaped eruptions on the surface of the deposit. Such features were not observed in uncoated control regions suggesting that the presence of the coating played a necessary role in the formation of these features.

\section{CONCLUSIONS}


Whisker growth for tin deposits on brass is greatly accelerated compared with equivalent deposits prepared on copper substrates. Furthermore, deposition conditions that result in more rapid whisker growth for tin deposits on brass, i.e. pulse electroplating, do not result in whisker growth for tin deposits on copper.

Accelerated whisker growth for tin deposits on brass substrates results from zinc diffusion to the surface of the deposit from the underlying substrate. Zinc diffusion and subsequent oxide formation at the surface of the deposit occurs within 1 day of electroplating. With increased storage time a network of zinc oxide is developed at the grain boundaries at the surface of the deposit. The area fraction of the deposit surface covered with zinc oxide increases with time.

Exposure to elevated temperature and humidity results in increased whisker growth rates due to increased zinc diffusion rates.

Whisker growth for tin deposits on brass has been demonstrated to be mitigated by electrochemical oxidation of the deposit surface. Electrochemical oxidation forms a layer of tin oxide on the deposit surface that is thicker than the native air formed oxide and serves as a barrier to subsequent zinc diffusion.

\section{ACKNOWLEDGEMENTS}

The authors would like to thank the UK EPSRC Innovative Electronics Manufacturing Research Centre for funding this research through the WHISKERMIT programme at Loughborough University. We would also like to acknowledge the contribution to the programme from our industrial collaborators; MacDermid plc, Rolls-Royce plc, Aero Engine Controls, NPL, MBDA UK Ltd., Park Air Systems Ltd. and Gen3 Systems. 


\section{REFERENCES}

1. The European Parliament and The Council of The European Union, Official Journal of the European Union, 46, L37 19 (2003).

2. S. Mathew, M. Osterman, M. Pecht, and F. Dunlevey, Circuit World, 35, 3 (2009).

3. R. Schetty, Circuit World, 27, 17 (2001).

4. A. Dimitrovska and R. Kovacevic, J.Electron. Mater., 38, 2516 (2009).

5. A. Dimitrovska and R. Kovacevic, J.Electron. Mater.,38, 2726 (2009).

6. A. Dimitrovska and R. Kovacevic, IEEE Trans. Electron. Packag. Manuf., 33, 193 (2010).

7. Y. Fukuda, M. Osterman, and M. Pecht, IEEE Trans. Electron. Packag. Manuf., 30, 36 (2007).

8. T. Fang, M. Osterman, and M. Pecht, Microelectron. Reliab., 46, 846 (2006).

9. H. Garich, H. McCrabb, E. Taylor, and M. Inman, ECS Transactions, 6, 153 (2007).

10. T. A. Woodrow and E. A. Ledbury, in IPC/JEDEC 8th International Conference on Lead-free Electronic Components and Assemblies, San Jose CA, April (2005),191-215.

11. S. C. Britton and M. Clarke, Trans. Inst. Met. Finish., 40, 205 (1964).

12. B. D. Dunn, European Space Agency Report STR-223, European Space Agency, Paris, France (1987).

13. G. Schon, J. Electron Spectrosc. Relat. Phenom., 2, 75 (1973). 
14. NIST, X-ray Photoelectron Spectroscopy Database, NIST Standard Reference Database 20, Version 4.1, http://srdata.nist.gov/xps/

15. W. Zhang and W. Ruythooren, in 2009 European Microelectronics and Packaging Conference (EMPC 2009), Vols. 1 and 2, Rimini, Italy, June (2009), 597-600.

16. S. M. Miller, U. Sahaym, and M. G. Norton, Metall. Mater. Trans. A, 41A, 3386 (2010).

17. K. Fujiwara and R. Kawanaka, J.Appl. Phys., 51, 6231 (1980).

18. S. Sakuyama and M. Kutami, Fujitsu Sci. Tech. J., 41, 217 (2005).

19. W. Ellis, D. Gibbons, and R. C. Treuting, in Growth and Perfection of Crystals:

Proceedings of an International Conference on Crystal Growth, edited by R. Dovemus, B.

Roberts, and D. Turnbull (Cooperstown, New York, 1958), pp. 102-120. 


\section{LIST OF FIGURES}

Figure 1 Secondary electron images showing the effect of substrate composition on whisker growth from $2 \mu \mathrm{m}$ tin deposits produced at $10 \mathrm{~mA} \mathrm{~cm}-2$. Analysis 12 months after deposition: (a) copper substrate and (b) brass substrate

Figure 2 Secondary electron images showing the effect of substrate composition on whisker growth from $5 \mu \mathrm{m}$ tin deposits produced by pulse plating (10\% duty cycle and $10 \mathrm{~Hz}$ pulse frequency). Analysis 9 months after deposition: (a) copper substrate and (b) brass substrate

Figure 3 Image comparing the surface appearance of $2 \mu \mathrm{m}$ tin deposits approximately 24 months after deposition: (a) copper substrate and (b) brass substrate

Figure 4 XPS analysis showing the effect of storage time on zinc oxide formation at the surface of $2 \mu \mathrm{m}$ tin deposits on brass: (a) 1 day after deposition and (b) 5 months after deposition

Figure 5 XPS sputter depth profile through the surface oxide on a $2 \mu \mathrm{m}$ tin deposit on brass 1 day after electrodeposition.

Figure 6 SEM analysis of a $5 \mu \mathrm{m}$ tin deposit on brass electroplated at $5 \mathrm{~mA} \mathrm{~cm}-2,6$ months after deposition (a) secondary electron image, (b) Sn L $\alpha$ x-ray map, (c) Zn L $\alpha$ x-ray map and (d) O Ka x-ray map

Figure 7 Secondary electron image showing the grain boundary structure on the surface of a $5 \mu \mathrm{m}$ tin deposit on brass prepared at $5 \mathrm{~mA} \mathrm{~cm}-2$. Analysed 6 months after deposition.

Figure 8 Secondary electron image showing extensive coverage of zinc oxide on the surface of a tin deposit after storage at room temperature for 14 months. $5 \mu \mathrm{m}$ deposit on brass prepared at $10 \mathrm{~mA} \mathrm{~cm}-2$.

Figure 9 SEM analysis of $5 \mu \mathrm{m}$ tin deposit $(10 \mathrm{~mA} \mathrm{~cm}-2)$ on brass 14 months after deposition (a) secondary electron image, (b) Sn L $\alpha$ x-ray map, (c) Zn L $\alpha$ x-ray map and (d) O Ka x-ray map 
Figure 10 SEM/EDX analysis of cross-sectioned $10 \mu \mathrm{m}$ Sn deposit on brass (electroplated at 20 mA cm-2) 10 months after deposition: (a) secondary electron image, (b) Zn L $\alpha$ X-ray map, (c) O Ka X-ray map and (d) $\mathrm{Cu} \mathrm{K} \alpha \mathrm{X}$-ray map

Figure 11 SEM/EDX analysis of cross-sectioned $3 \mu \mathrm{m}$ Sn deposit on brass (electroplated at $20 \mathrm{~mA} \mathrm{~cm}-2$ ) after 28 days at $55^{\circ} \mathrm{C} / 85 \% \mathrm{RH}+3$ months subsequent storage at room temperature: (a) secondary electron image, (b) Sn L $\alpha$ X-ray map, (c) Zn L $\alpha$ X-ray map, (d) O K $\alpha$ X-ray map and (e) Cu Ka X-ray map

Figure 12 Secondary electron images showing the effect of elevated temperature and humidity on whisker growth for $3 \mu \mathrm{m}$ Sn deposits on brass (electroplated at $20 \mathrm{~mA} \mathrm{~cm}-2$ ): (a) and (c) stored for 28 days at $55^{\circ} \mathrm{C} / 85 \%$ relative humidity followed by 16 days at room temperature and (b) and (d) 44 days at room temperature

Figure 13 AES analysis of a whisker on a $5 \mu \mathrm{m}$ tin deposit on brass after 14 months storage at room temperature: (a) surface of whisker prior to sputtering and (b) surface of whisker after short sputter to remove surface oxide

Figure 14 XPS analysis showing significantly reduced Zn content on the surface of $2 \mu \mathrm{m}$ tin deposits electrochemically oxidised at $1.2 \mathrm{~V}$ vs. SCE immediately after tin deposition Figure 15 XPS analysis comparing the Sn 3d5 peak for Sn electrodeposits on brass: (a) $2 \mu \mathrm{m}$ deposit 1 day after electroplating, (b) $2 \mu \mathrm{m}$ deposit 5 months after electroplating and (c) $2 \mu \mathrm{m}$ deposit electrochemically oxidised at $1.2 \mathrm{~V}$ vs. SCE immediately after electroplating Figure 16 Secondary electron comparing whisker growth for $2 \mu \mathrm{m}$ tin deposits on brass 4 months after deposition. Samples electroplated at $20 \mathrm{~mA} \mathrm{cm-2:} \mathrm{(a)} \mathrm{native} \mathrm{air} \mathrm{formed} \mathrm{oxide}$ and (b) surface electrochemically oxidised at $1.2 \mathrm{~V}$ vs. SCE in pH 8.4 borate buffer solution Figure 17 XPS analysis showing the Zn content on the surface of $2 \mu \mathrm{m}$ tin deposits electrochemically oxidised at $1.2 \mathrm{~V}$ vs. SCE immediately after deposition. Analysis carried out 20 weeks after tin deposition and electrochemical oxidation 
Figure 18 XPS sputter depth profile through surface oxide of a $2 \mu \mathrm{m}$ tin deposit on brass electrochemically oxidised at $1.2 \mathrm{~V}$ vs. SCE. Analysis 9 months after tin deposition and electrochemical oxidation

Figure 19 Schematic showing possible mechanism for zinc oxide formation: (a) shortly after deposition (within 1 day) a thin layer of zinc oxide forms on the surface of the deposit, (b) with time zinc oxide builds up at the surface connected grain boundaries (c) zinc oxide penetrates into the tin grain boundaries and (d) inward diffusion of oxygen results in zinc oxide formation at the grain boundaries deep into the tin deposit. Zinc oxide coverage also extends into the grain interiors on the surface of the deposit 
(a)

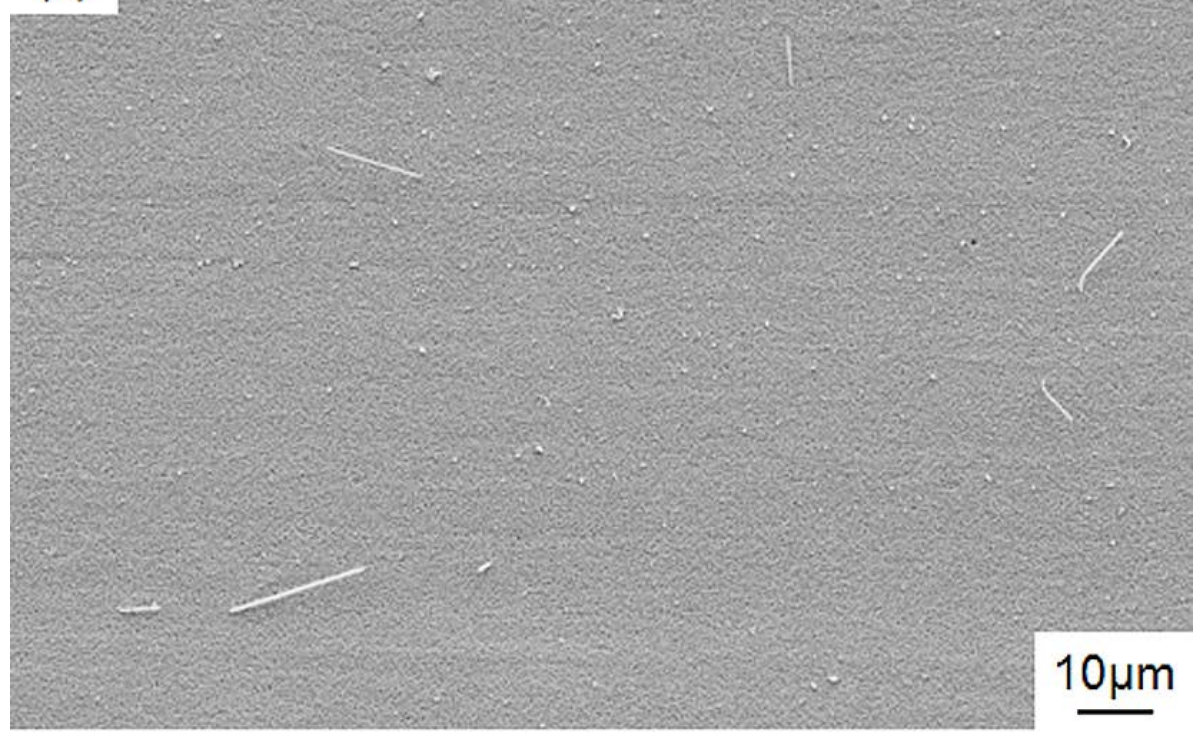

(b) $3 \cdot 3 \%$.

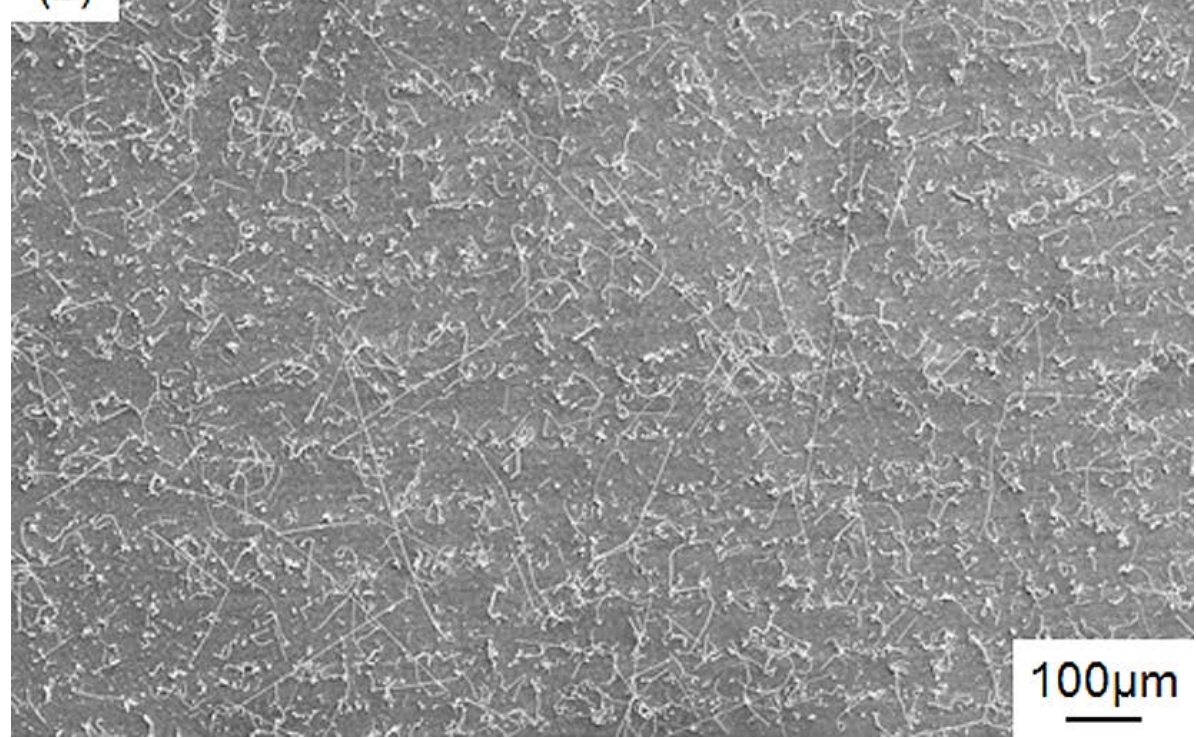

Figure 1 
(a)

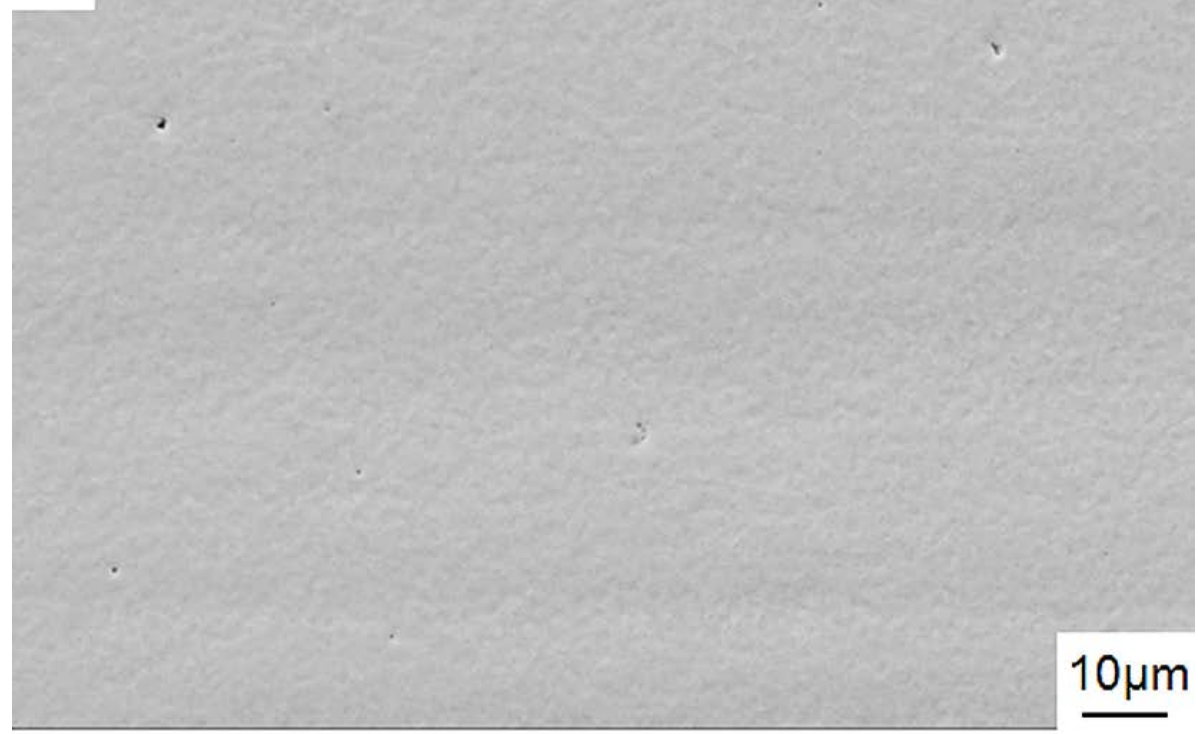

(b)

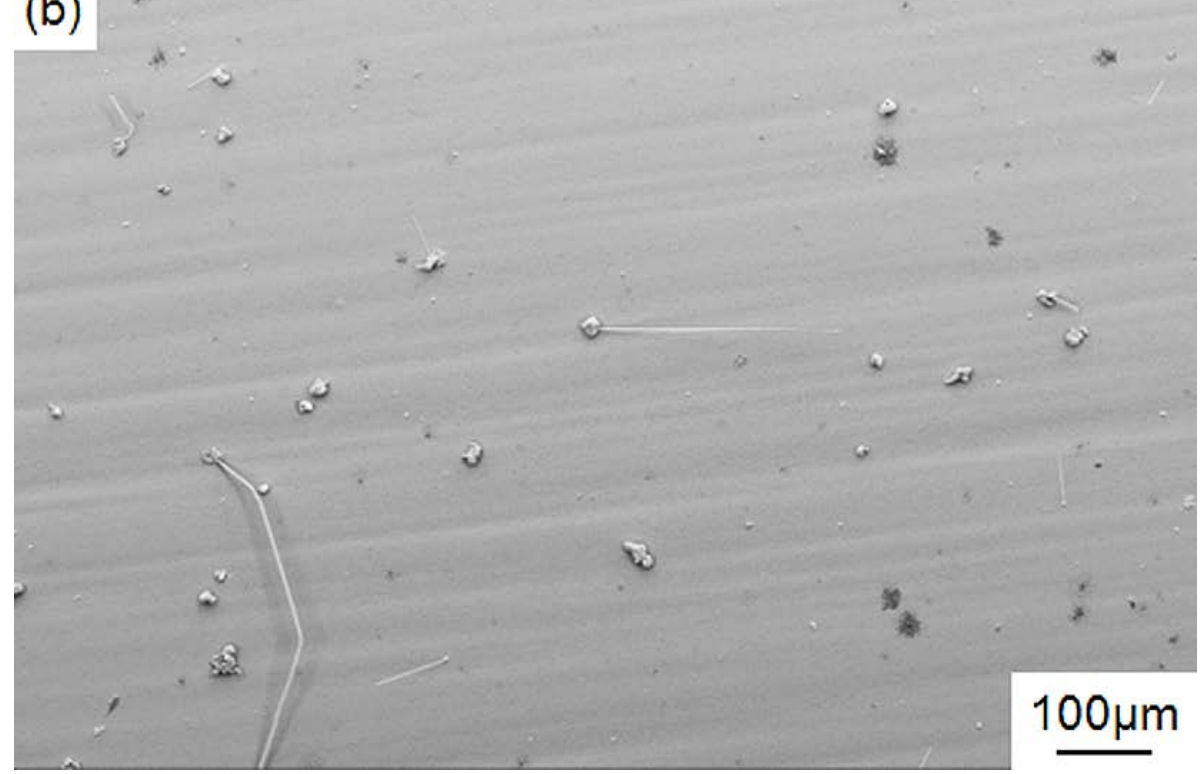

Figure 2 


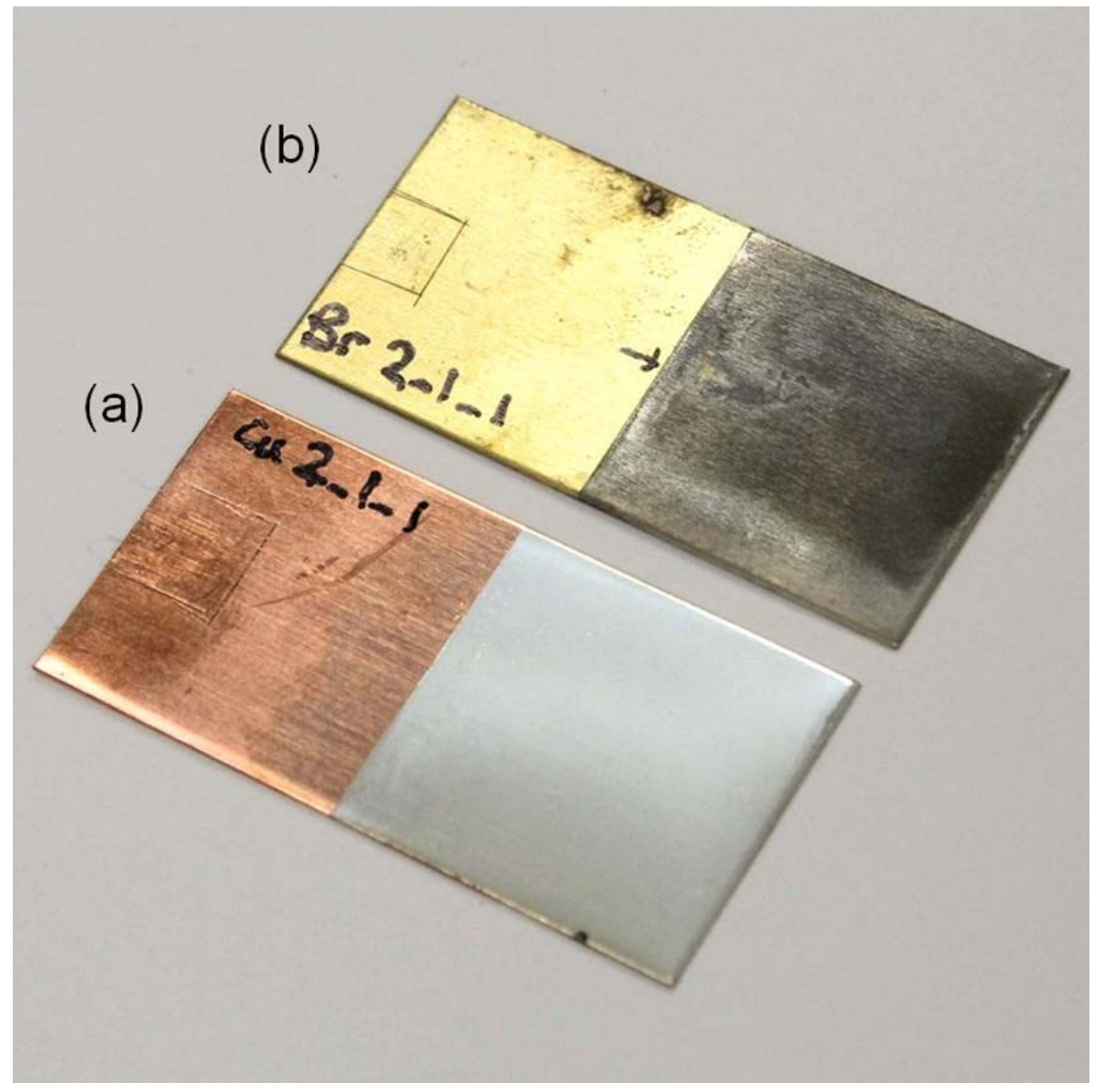

Figure 3 

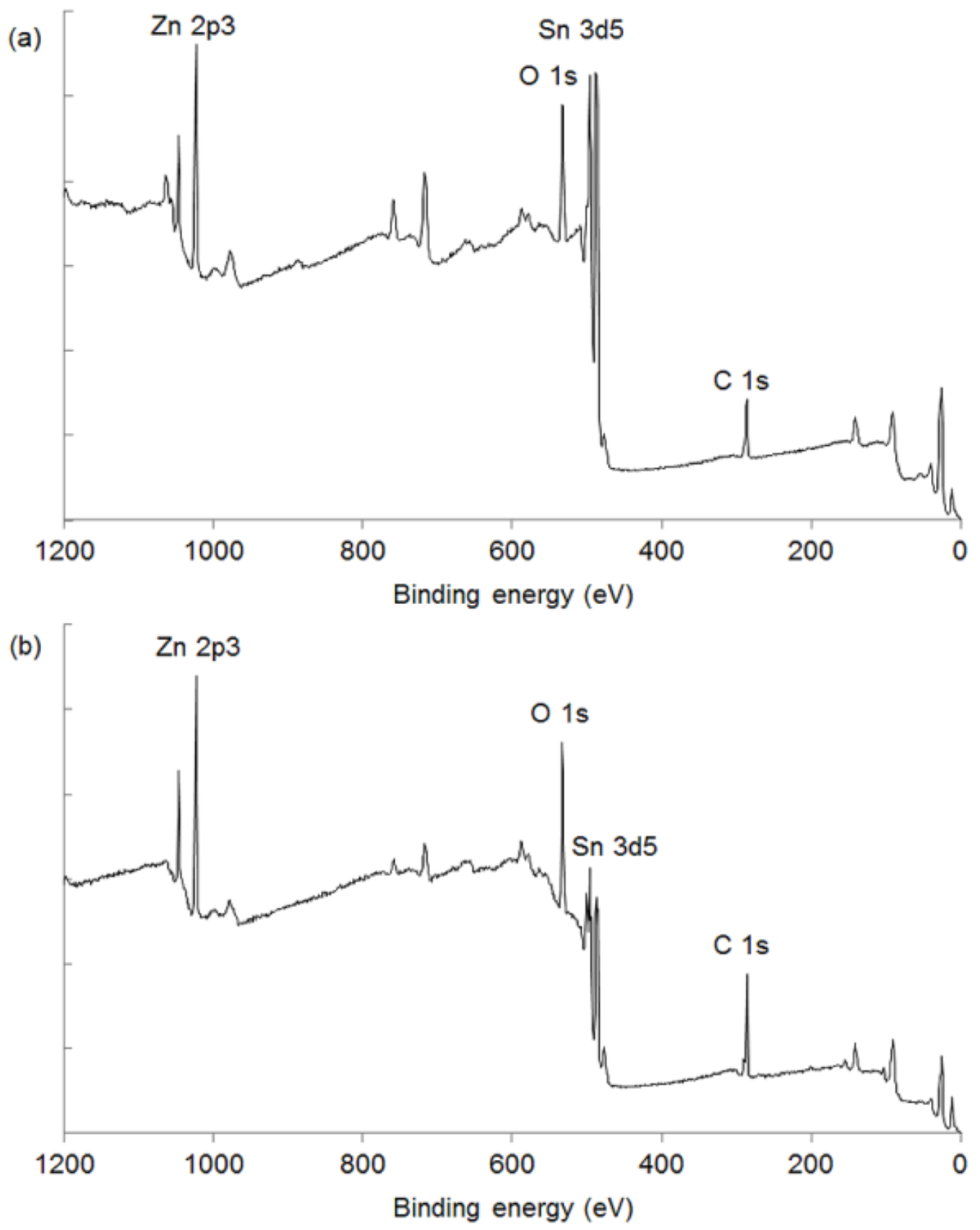

Figure 4 


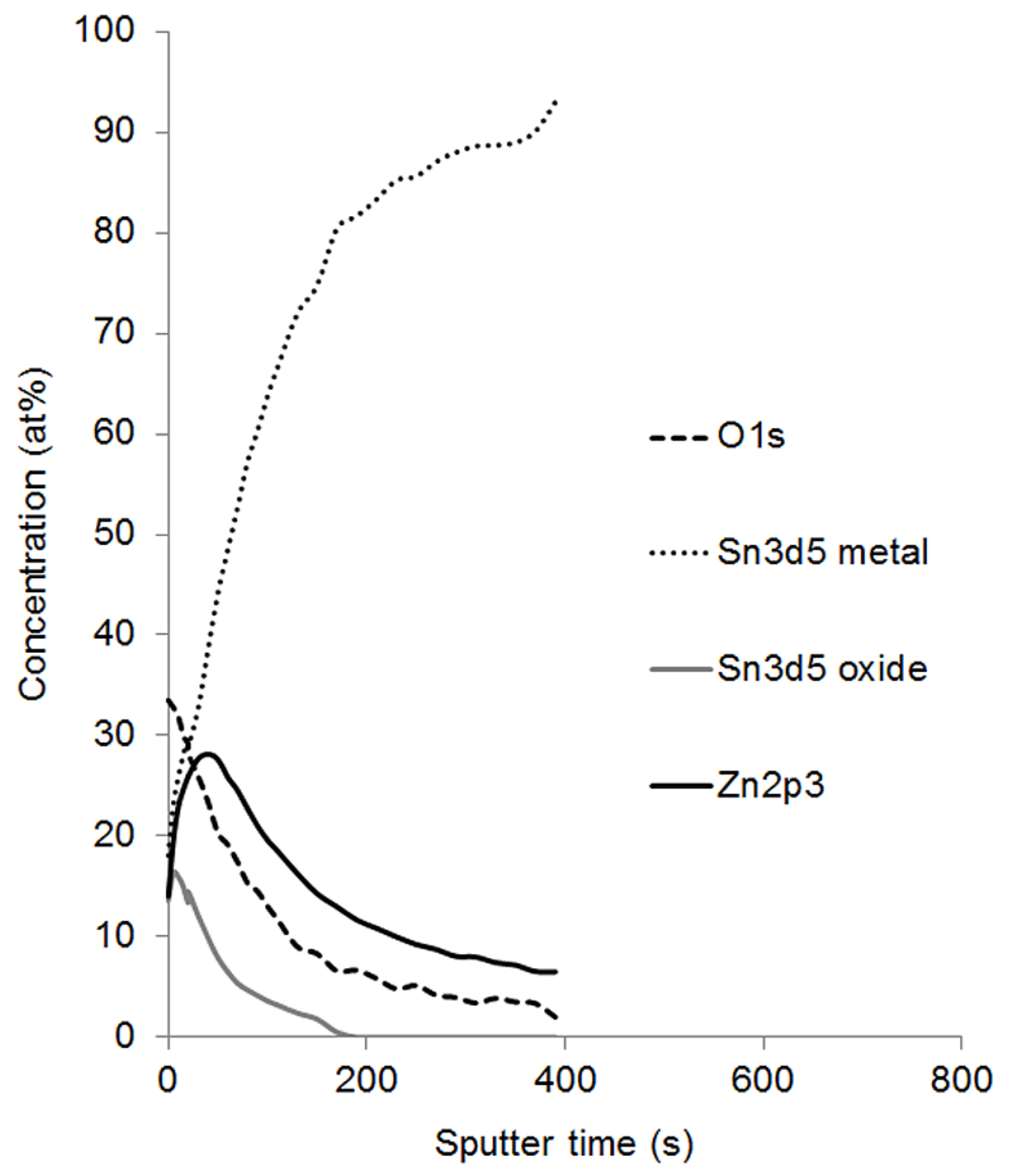

Figure 5 

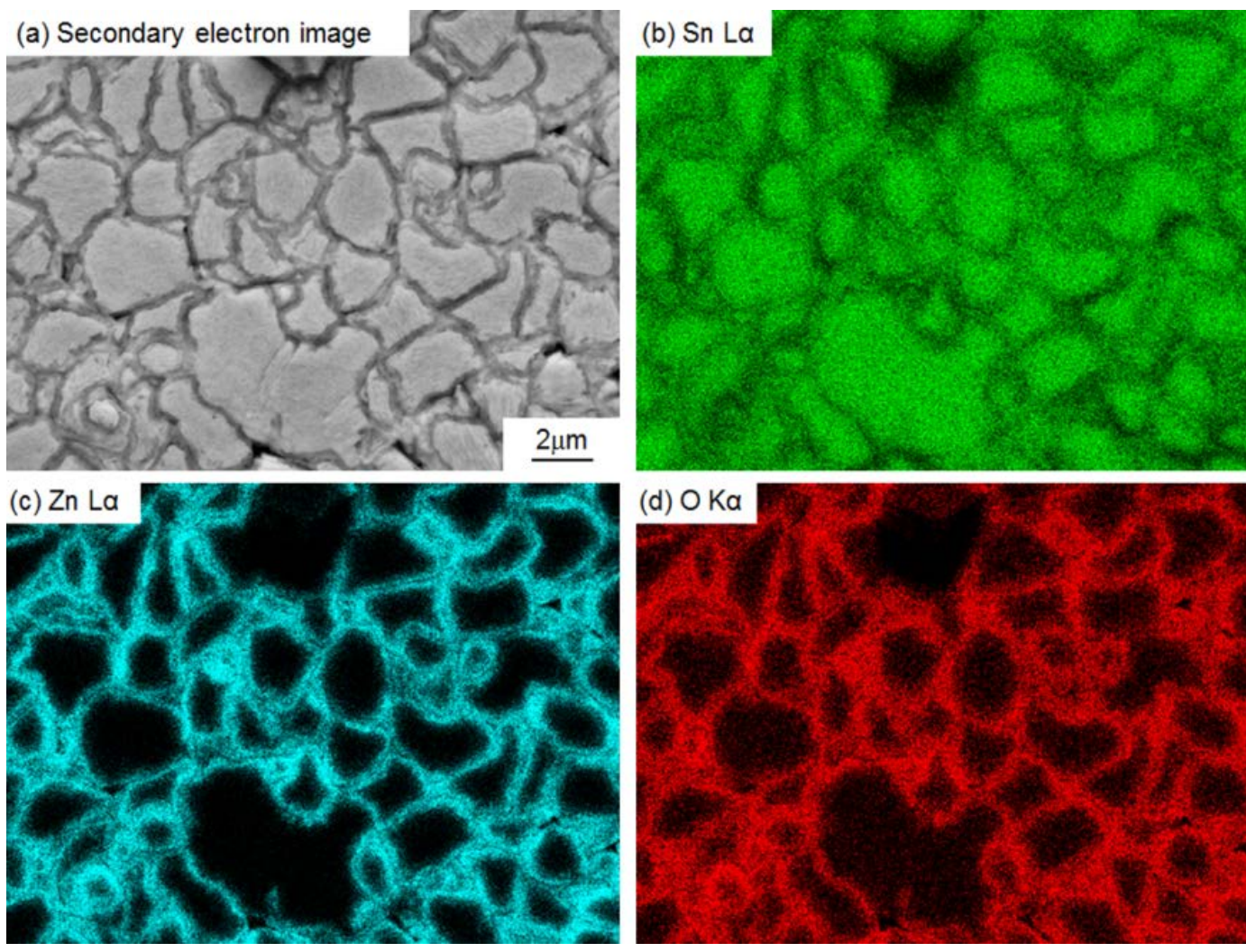

Figure 6 


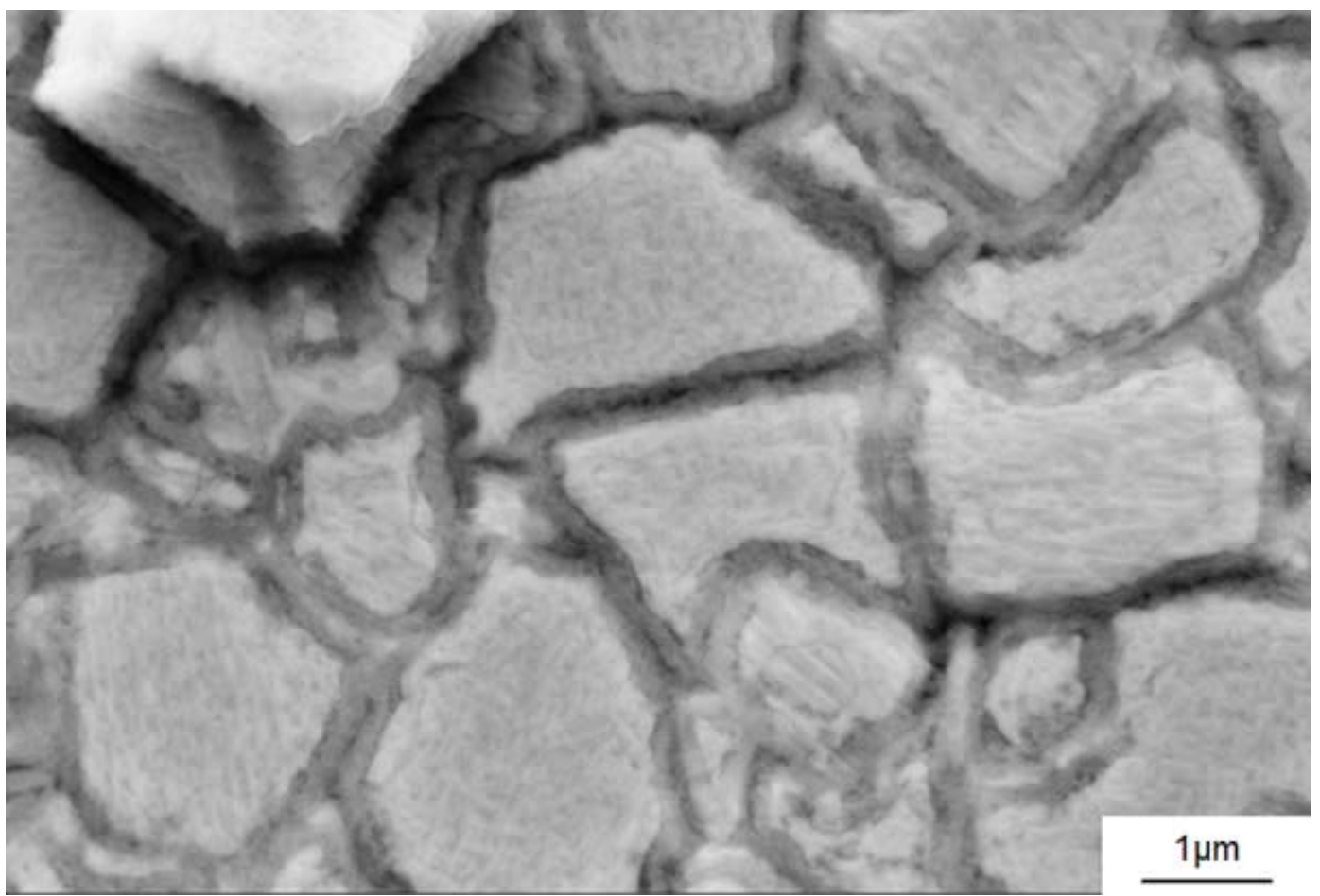

Figure 7 


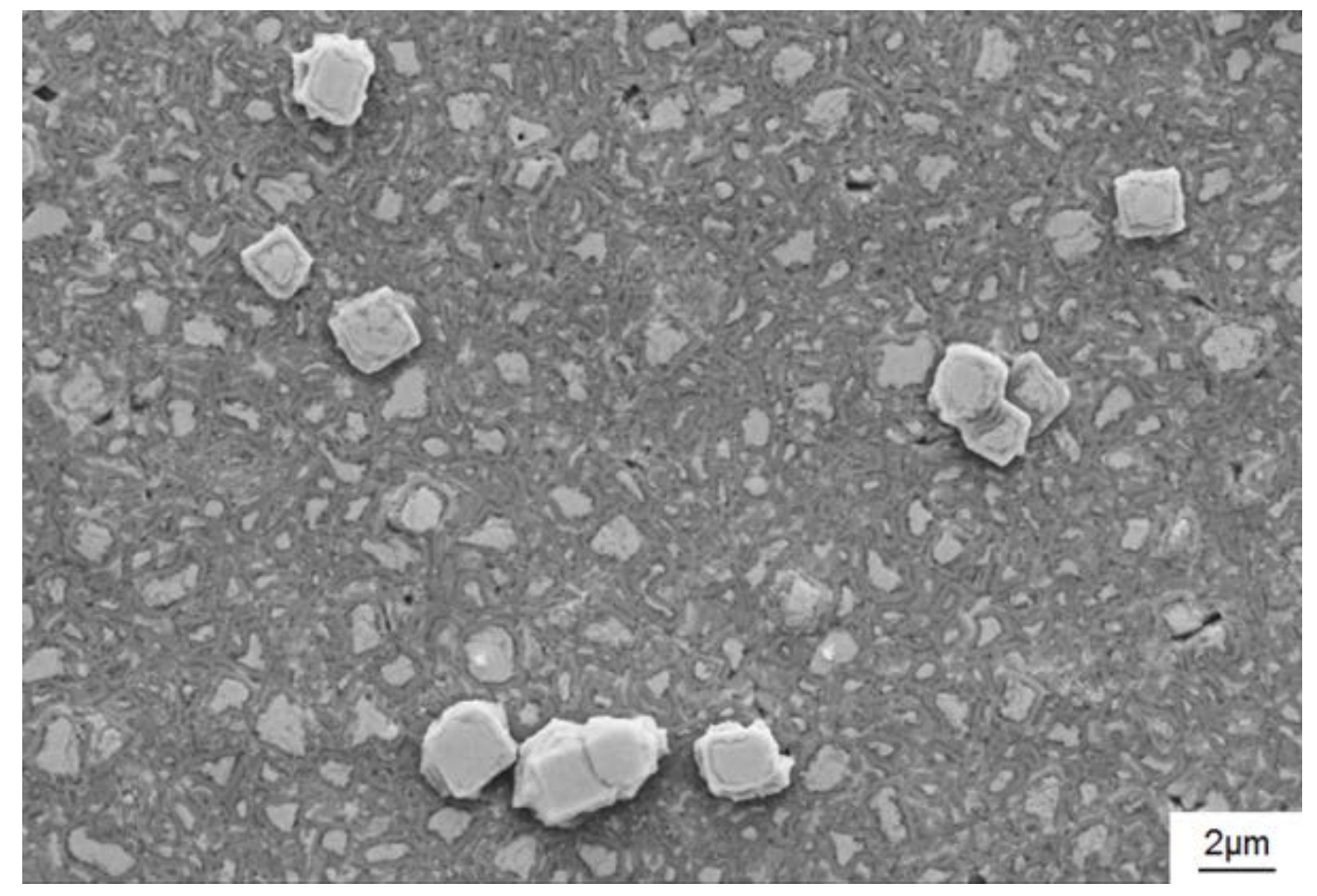

Figure 8 

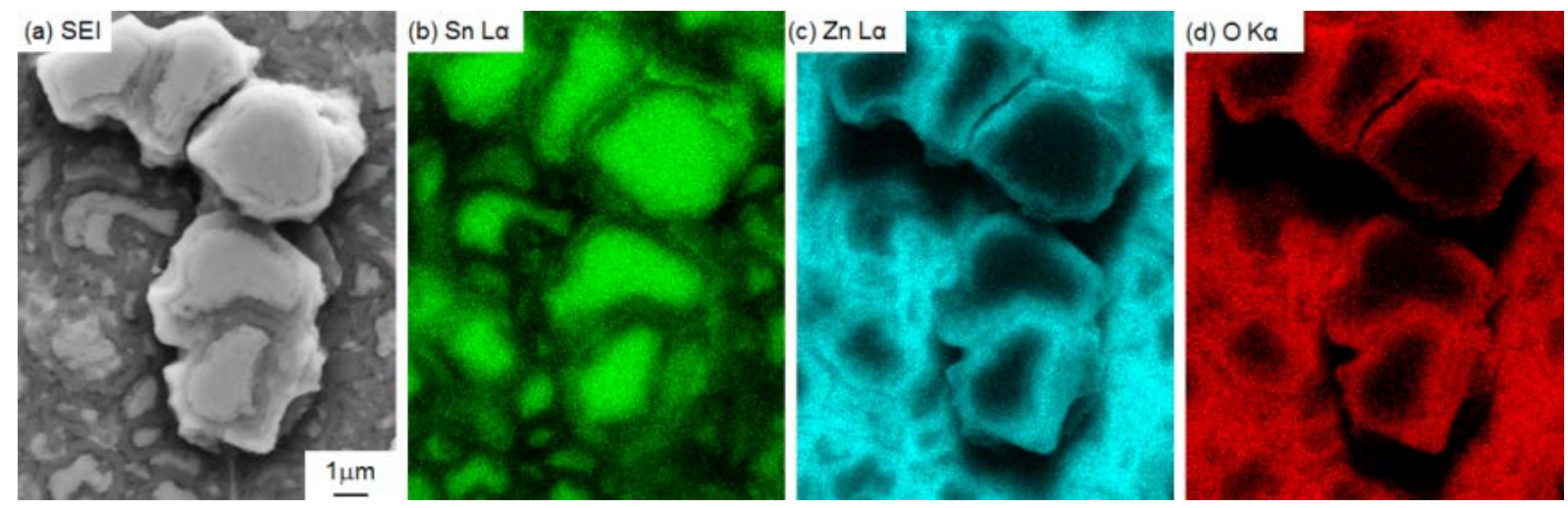

Figure 9 

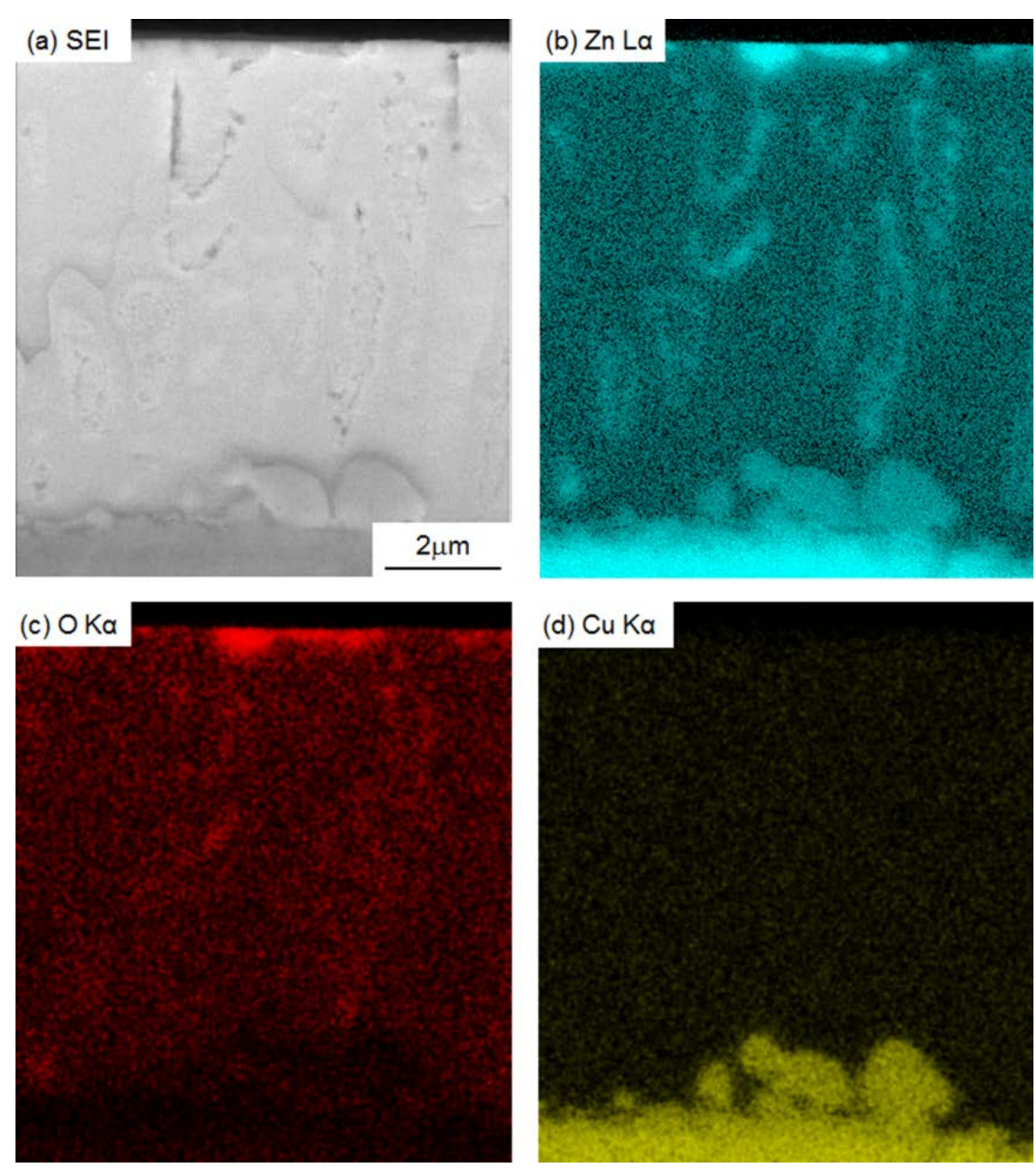

Figure 10 

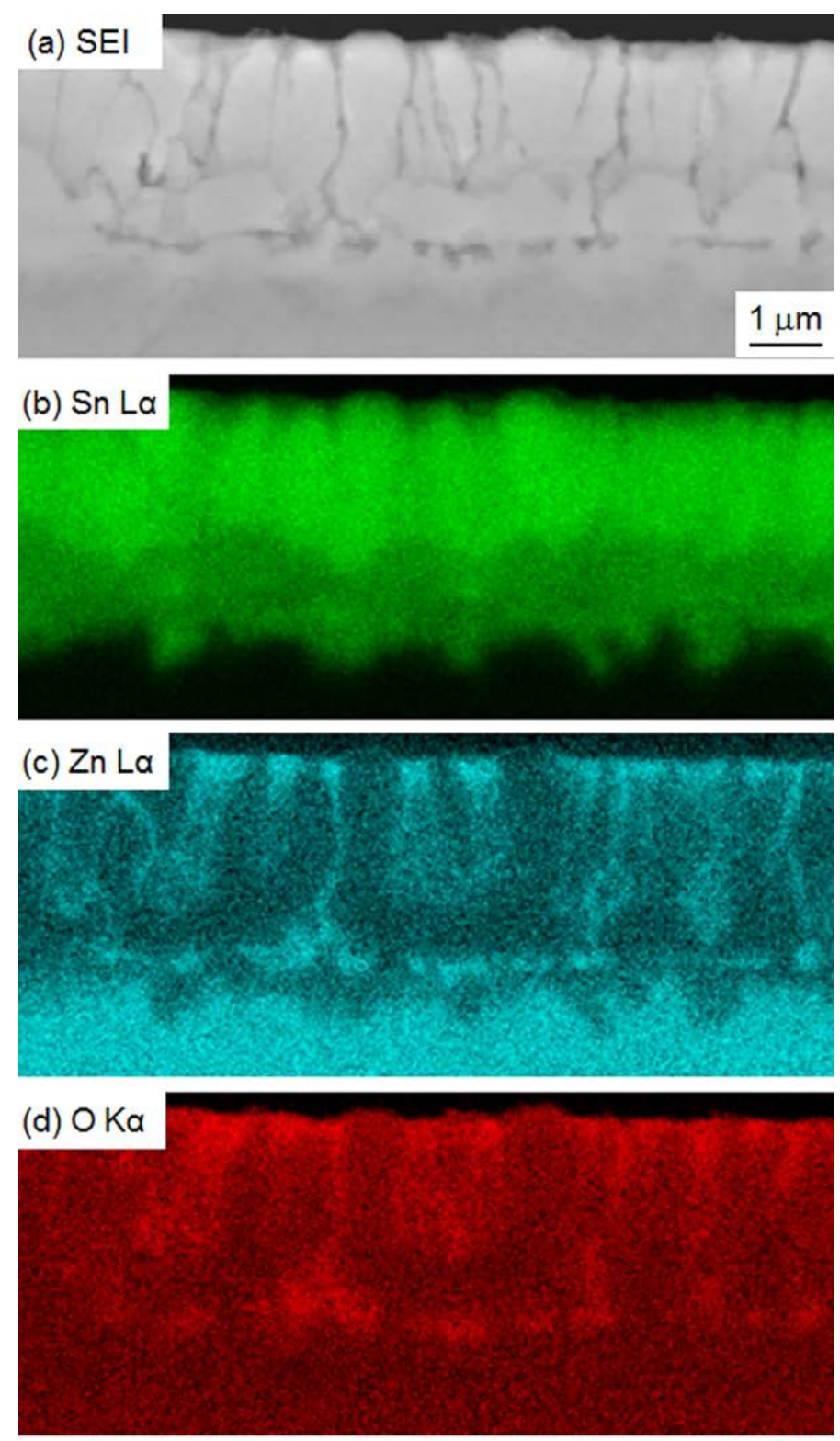

(e) $\mathrm{Cu} \mathrm{Ka}$

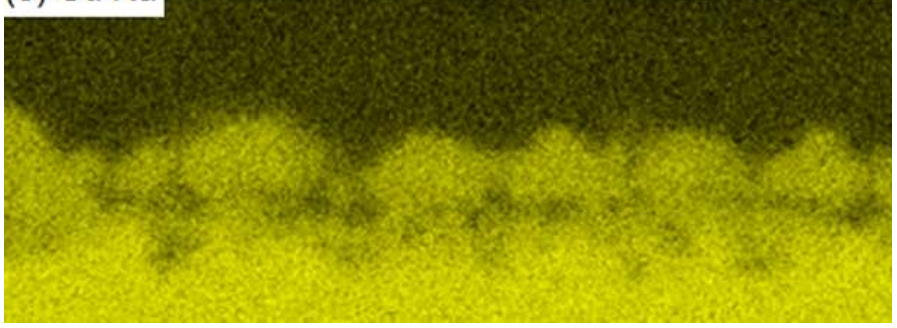

Figure 11 
(a)

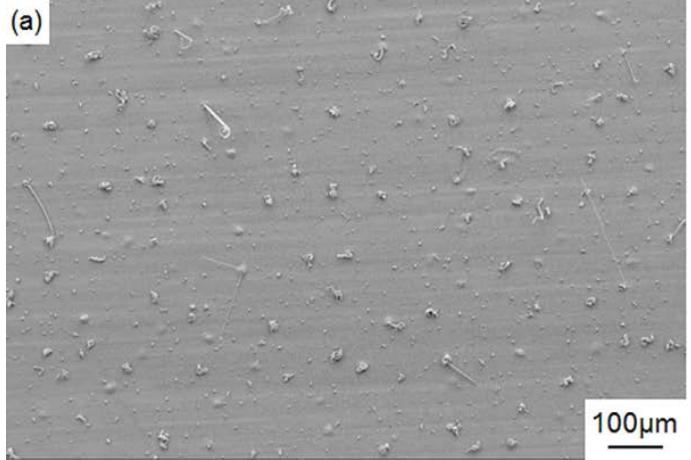

(c)

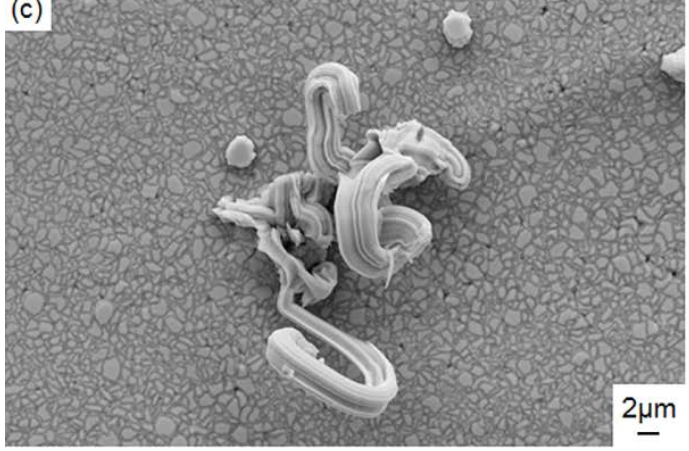

(b)

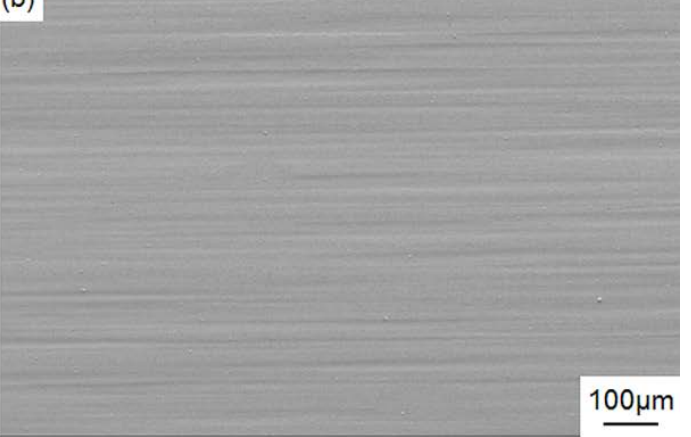

(d)

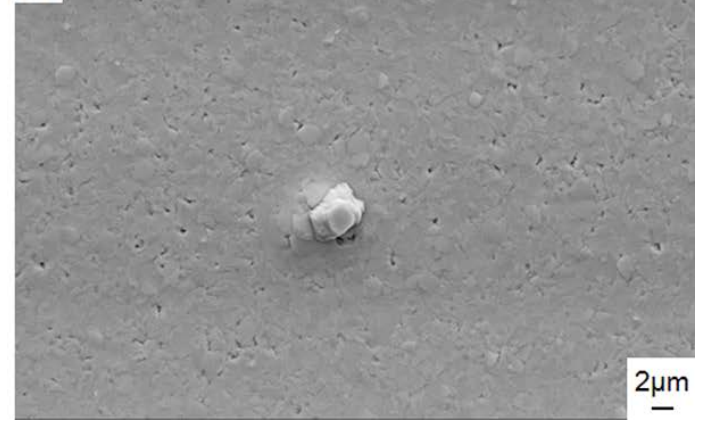

Figure 12 

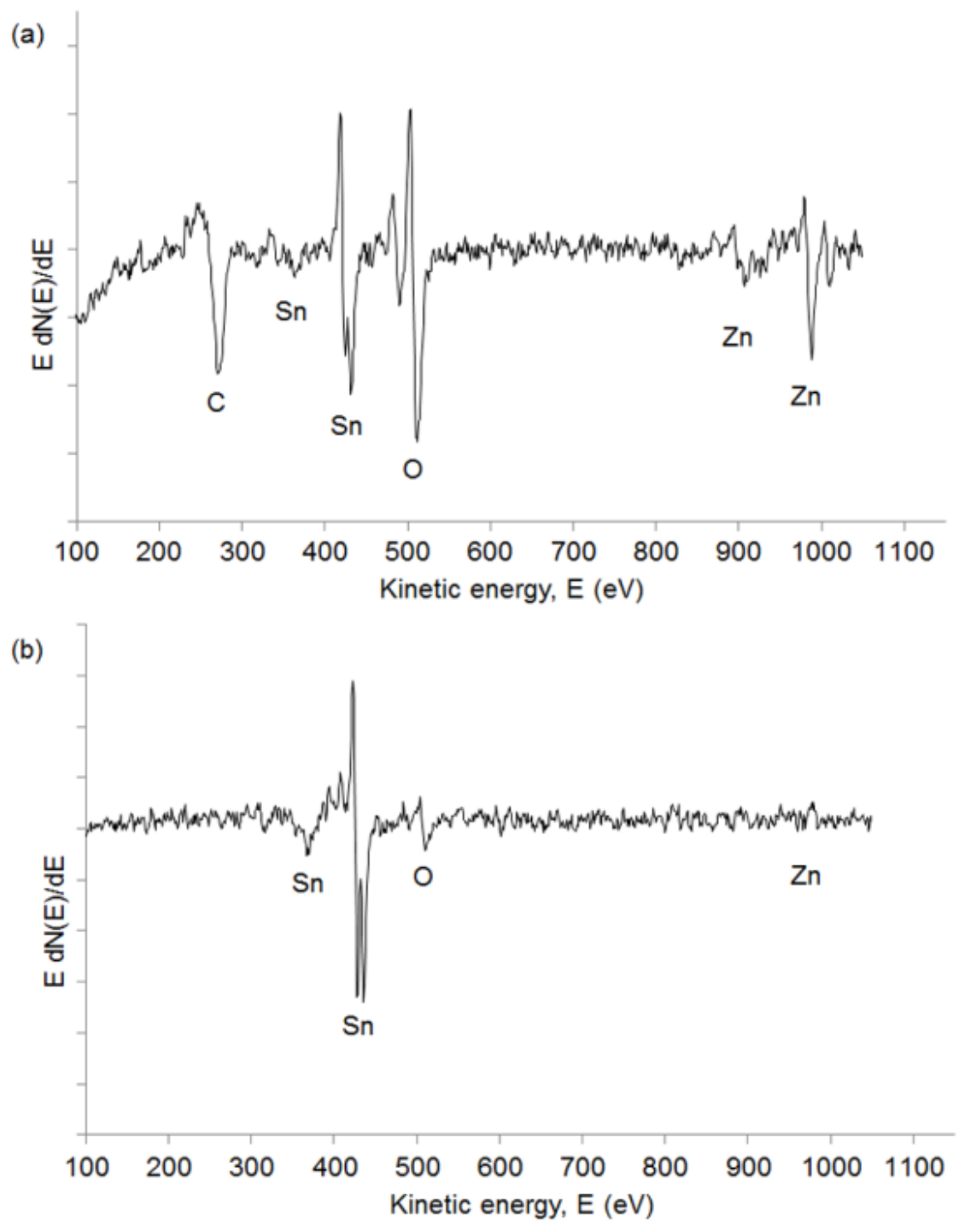

Figure 13 


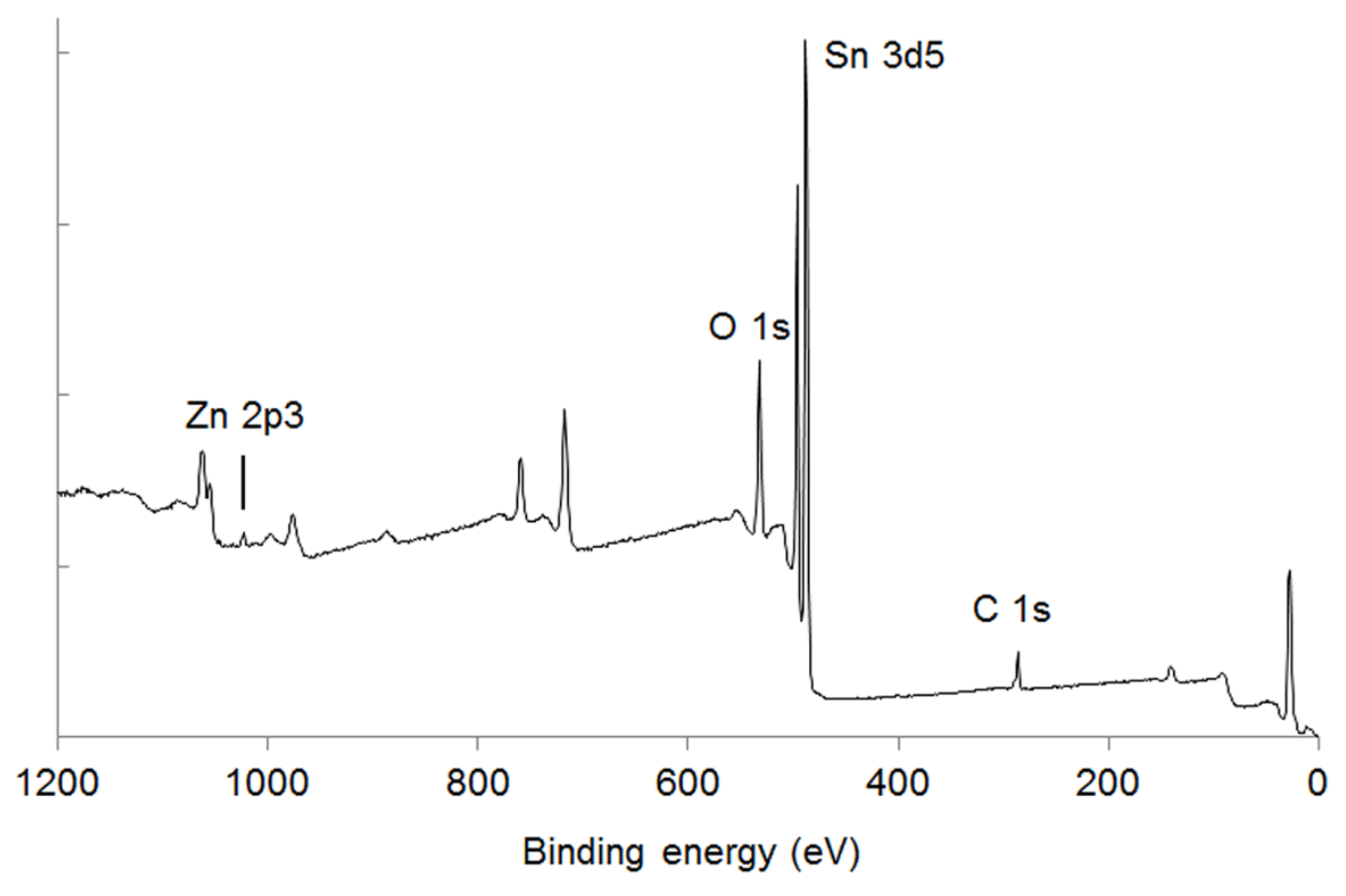

Figure 14 
(a)

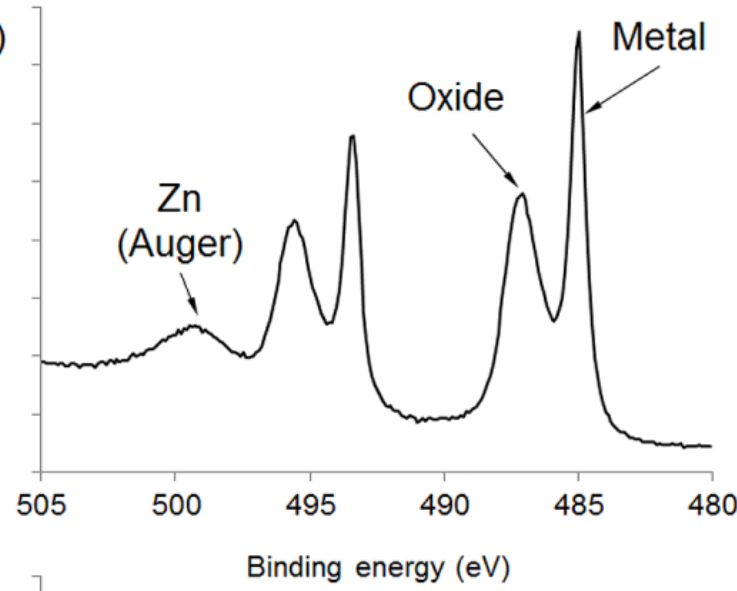

(b)

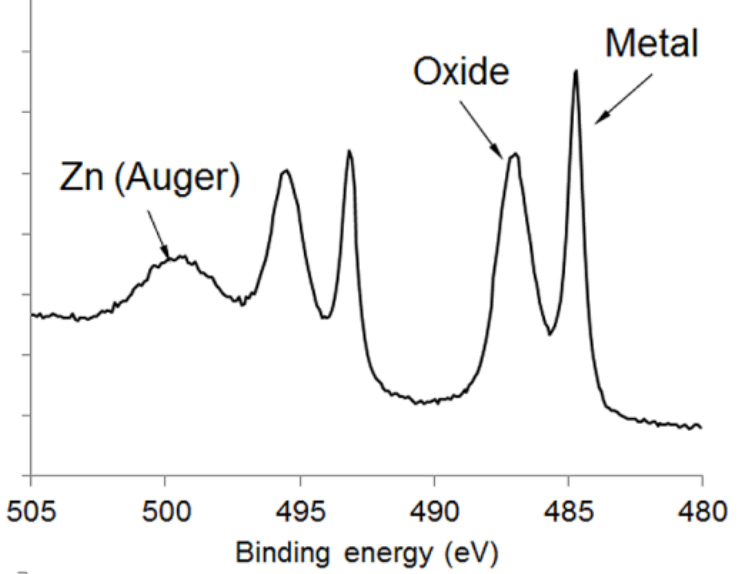

(c)

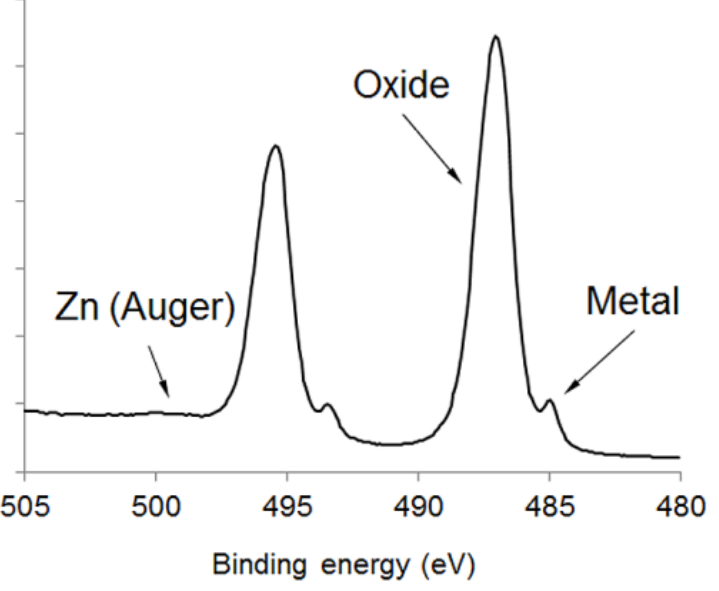

Figure 15 
(a)

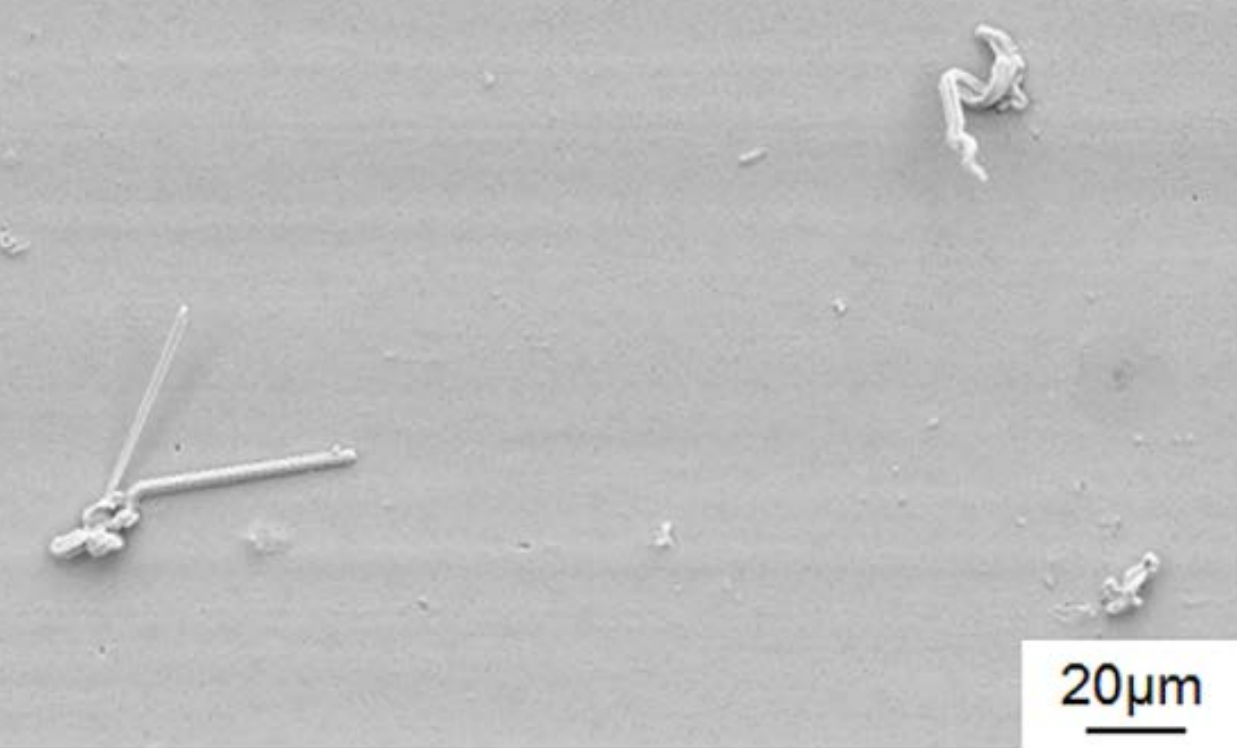

(b)

$20 \mu \mathrm{m}$

Figure 16 


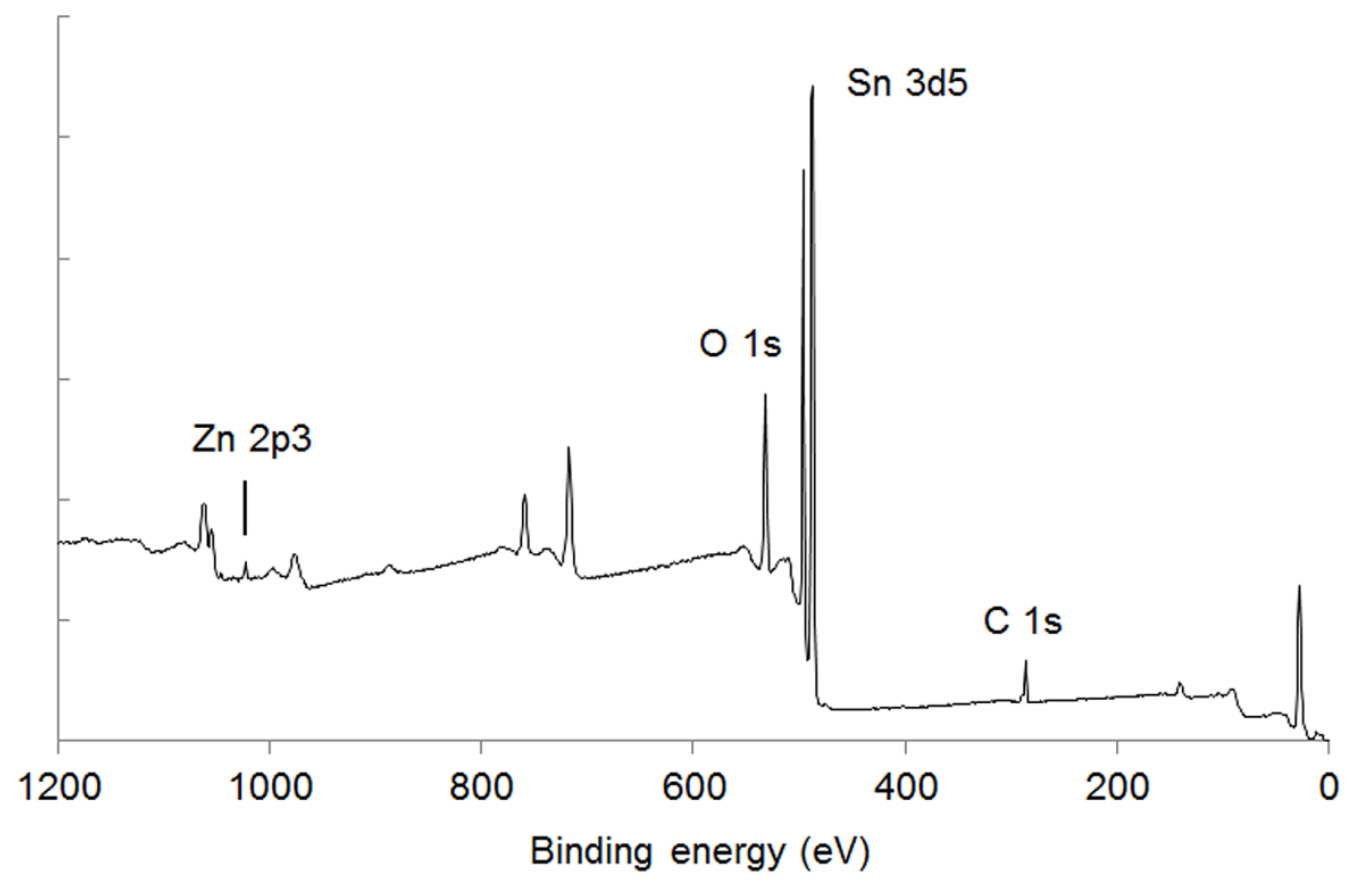

Figure 17 


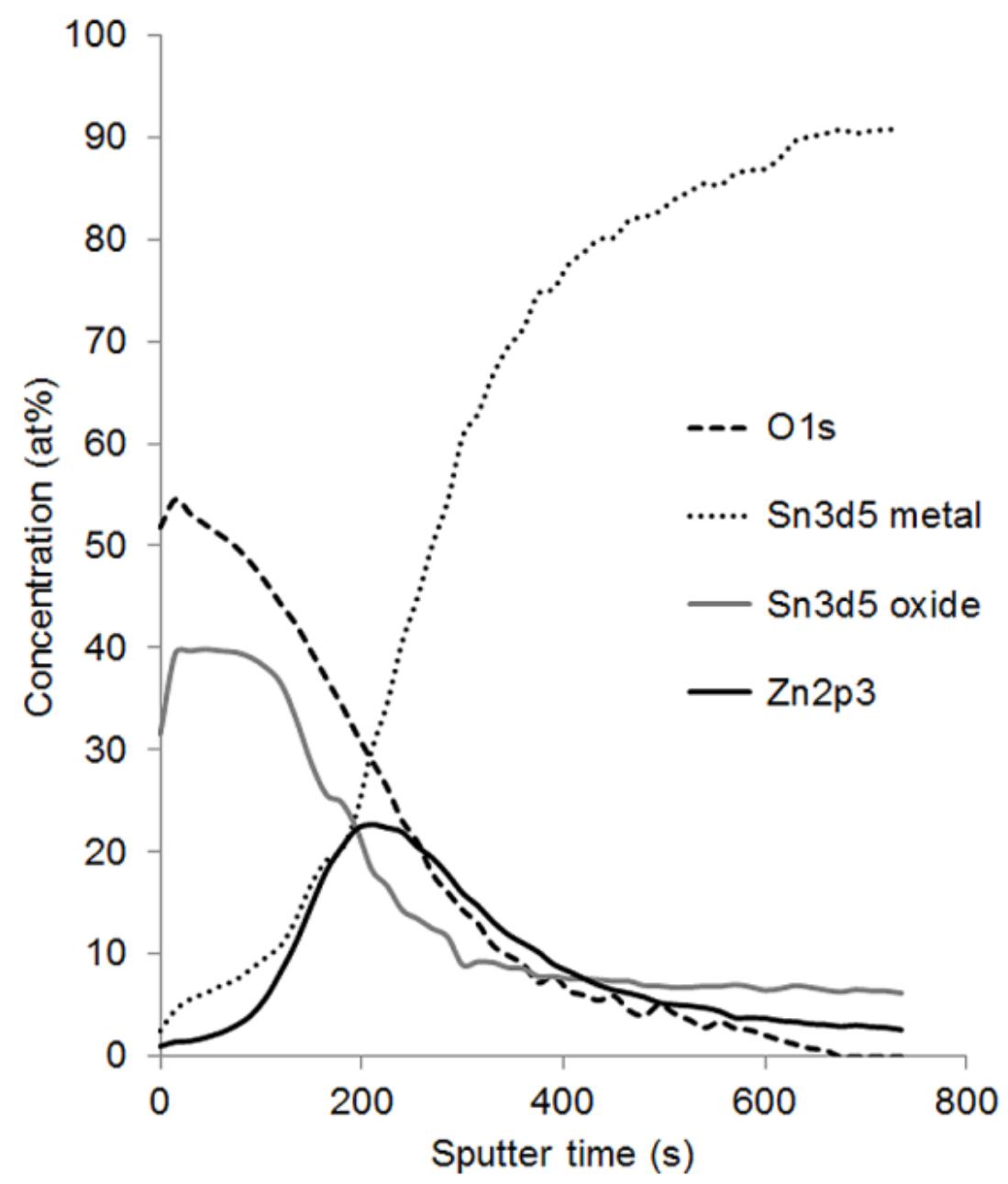

Figure 18 
(a)

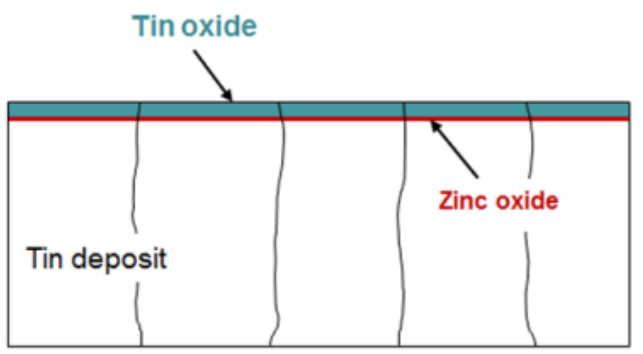

(c)

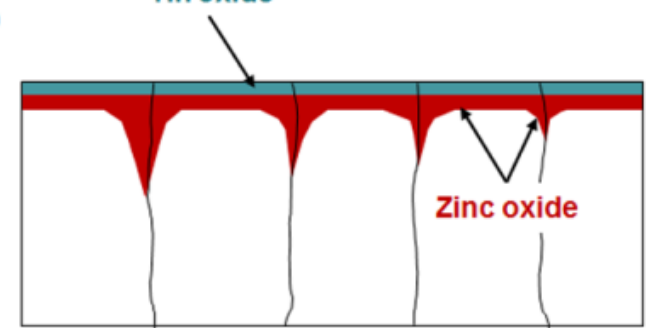

(b)

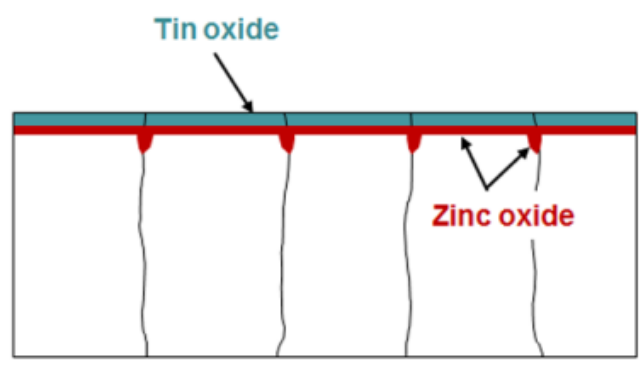

(d)

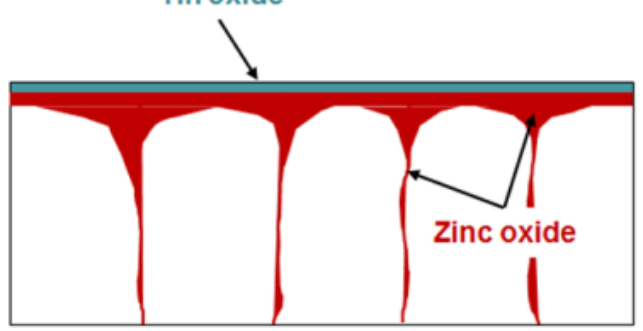

Figure 19 